Arqueología y Sociedad,

№ 21, 2010

\title{
Evidencias arQueOlógicas en CAMATA TAMBO, TAMBO INCA UBICADO EN EL VALLE ALTO DE Moquegua, Andes sur-Centrales
}

\section{Sofía Chacaltana Cortez}

\begin{abstract}
Resumen
En base a excavaciones y análisis paleobotánicos realizados en las qollqas (cuartos de almacenamiento) de Camata Tambo, tambo Inca ubicado a 2.800 m.s.n.m. en el valle alto de Moquegua, se propone que las qollqas de esta institución imperial tuvieron una alta sofistificación tecnológica que sugiere que estos almacenes estuvieron diseñados para almacenar y controlar productos de procedencia regional que fueron distribuidos a ciertos grupos locales y, a localidades distantes del Colesuyo (e.g. el altiplano). En este artículo se plantea que a pesar de que Camata Tambo estuvo ubicado en una zona marginal del imperio como fue la sub-región del Colesuyo (parte del Collasuyo), tuvo importantes funciones político-económicas en la zona y proveyó de productos del valle a los emergentes y más poderosos grupos del circum-titicaca. Además, a través de estas evidencias y de excavaciones realizadas en zonas de almacenamiento de Camata Pueblo, comunidad local ubicada a menos de $100 \mathrm{~m}$ del tambo, se sugiere que la infraestructura y burocracia imperial desarrollada a través de Camata Tambo, impactó de manera significativa a específicos pueblos locales de la fragmentada y heterárquica sociedad Estuquiña (Intermedio Tardío 1100 d.C. - 1450 d.C.), sociedad que habitó la región antes y durante la ocupación imperial en el valle (Horizonte Tardío 1450 d.C. - 1532 d.C.). Finalmente, se propone que los tambos fueron instituciones que además de haber servido como establecimientos de hospedaje y almacenamiento de los viajantes imperiales, cumplieron importantes roles administrativos y políticoeconómicos imperiales; y que la función de éstas instituciones Incas en zonas marginales es más amplia y ambigüa que en las zonas administradas directamente por el imperio, llamando la atención sobre el uso de categorías institucionales en el Tawantinsuyo.
\end{abstract}

Palabras clave

Camata Tambo, Colesuyo, Tambos Incas, Almacenaje Inca, Colcas

\begin{abstract}
Archaeological excavations together with paleobotanical analyses conducted in qollqas (Inca storage rooms) at Camata Tambo, an Inca tambo (waystation) located 2,800 m.a.s.l in the upper Moquegua Valley of Southern Peru, suggest that these storage structures incorporated a sophisticated technology designed for storing and controlling multiple types of products from the Colesuyo region including local and distant coastal products. Apparently, this economic surplus based on foodstuffs was later distributed to nearby and far-away populations (e.g. in the altiplano). In addition, although Camata Tambo was in a 'marginal' locale of the empire, the site had important political economic functions in the area such as providing valley products to the emerging and more powerful altiplano elites. Further, data collected from excavations conducted at Camata Pueblo, a local community adjacent to the tambo (less than 100 meters), indicate that this community was greatly transformed by the close interactions with imperial infrastructure and bureaucracy that developed through Camata Tambo. The data presented indicate that waystations were institutions that not only provided food and lodging to imperial travelers, but which also had important political economic and administrative imperial roles. Finally, excavations suggest that the operation of these Inca institutions in marginal zones was more ambiguous and 'open' than in regions more directly controlled by the empire.
\end{abstract}

Keywords

Camata Tambo, Colesuyo, Inca Way stations, Inca storage, Colcas 


\section{Los TAMBOS INCAS}

Los tambos fueron instalaciones sistemáticamente construídas cada 15 a $25 \mathrm{~km}$ de distancia a lo largo de los aproximadamente 40,000 km de caminos principales y secundarios del más grande imperio de las Américas precolombinas. Estas instalaciones estuvieron sustentadas por el imperio, administradas por burócratas imperiales con ayuda de los líderes locales, y al beneficio de los viajantes que cumplían órdenes imperiales (tanto militares, económicas, religiosas, u oficiales bajo tareas imperiales). Los tambos junto con los caminos Incas conectaron los principales centros administrativos y zonas de interés económico del imperio en las provincias, y en la mayoría de los casos fueron sustentados y servidos por los pobladores de las comunidades adyacentes o cercanas que cumplieron en ellos su impuesto de trabajo rotativo o mit'a al imperio Inca. Estas instituciones funcionaban bajo el sistema de reciprocidad y redistribución característico de la economía andina e Inca, en donde los mitamakunas (los pobladores trabajando bajo auspicio del imperio) suplían los almacenes de productos agrícolas tanto locales como foráneos, así como productos de primera necesidad como tejidos, apargatas, paja, entre otros (D'Altroy 2004).

Influenciados por los estudios llevados a cabo por el investigador John Hyslop (1984) en la década de los 80 , el más amplio y conciso estudio sobre los caminos y tambos Incas en el Tawantinsuyo; en la actualidad, la mayoría de los estudios sobre los tambos pone atención sobre la articulación de los mismos al camino Inca, y la función de este sistema de transporte (tambos y caminos) como nodo de conexión e interconexión con otras zonas y/o regiones de interés imperial (Chacaltana 2010). Es así que a pesar de que estos estudios han ayudado a entender la sofisticada infraestructura desarrollada por el imperio, han dejado de lado los procesos de articulación social y económicos ocurridos en las comunidades locales durante la presencia de las instituciones imperiales. Sugiero que es interesante e importante observar la articulación y la dinámica desarrollada entre el imperio y las comunidades andinas de manera detallada, las cuales pueden ser observadas a través de los tambos, y que no ha sido anteriormente explorada por los investigadores andinos.

Por otro lado, hoy en día existen ciertas ambigüedades de lo que constituye un tambo. Los motivos los he enunciado en un trabajo anterior (Chacaltana 2010) y escapan a los objetivos del presente artículo, pero de manera general, se está de acuerdo de los aspectos físicos de un tambo. Los tambos se distinguen físicamente por ser edificaciones ${ }^{1}$ de dimensiones pequeñas en comparación a otras instituciones imperiales como los centros administrativos Incas. Como mínimo, estos edificios estan compuestos por lugares públicos o kanchas que fueron recintos rectangulares con cuartos internos también de forma rectangular, por kallankas, o cuartos rectangulares y alargados de probables funciones administrativas o de descanso, y por estructuras de almacenamiento o qollqas (Hyslop 1984). Pero, a pesar de que existen características arquitectónicas comunes, no hay dos tambos Incas iguales en todo el imperio. Es debido a esta variabilidad arquitectónica que algunos investigadores sugieren que éstos edificios cumplieron diversas funciones como por ejemplo tener roles ceremoniales y/o económicos, o político-administrativos, artesanales, entre otros (ver Bárcena 1988; Flores y Herrero 2006; Helsley 1980; INC 2004; Morris 1992a; Tschauner 2001).

Sin embargo, a pesar que se tiene claro algunas de sus funciones y tenemos ideas de algunas otras, aún desconocemos; ¿Qué roles jugaron los tambos en diferentes regiones de los Andes?, ¿En qué extensión fueron sus roles determinados por el imperio o por el gobierno local?, y ¿Qué es lo que constituye un tambo? Todas éstas son preguntas que he estado explorando en mis investigaciones durante los últimos años, y aunque aún no pueden ser contestadas, son las

1 Aquí utilizo el término "edificios" para hacer referencia a ciertas características formales y funcionales de los tambos incas, que son un conjunto de espacios, que aunque tuvieron variaciones, tenían espacios en común y tenían funciones determinadas. Estas características tanto formales como funcionales son definidas en las siguientes líneas. 
que articulan mis investigaciones y, por ende el presente artículo.

Es asi que las investigaciones que estan siendo llevadas a cabo en el Colesuyo por la autora de este artículo se enfocan en los siguientes puntos: En primer lugar, observar la articulación de los tambos o de la infraestructura imperial con las poblaciones locales. En este punto nos interesa analizar las diferentes transformaciones ocurridas por los diferentes agentes que formaron las comunidades andinas (personas de elite y de no-elite), en especial de sociedades nojerárquicas, heterárquicas y fragmentadas ubicadas en diversos ecosistemas, como las varias comunidades que habitaron el Colesuyo. En segundo lugar, entender a los tambos como instituciones imperiales de naturaleza flexible que provocaron un impacto económico y político en las zonas marginales o en zonas donde la presencia imperial fue de control o de influencia, y no de naturaleza administrativa o de control directo. ${ }^{2}$ Y En tercer lugar, ver la manera cómo los tambos se transformaron en las instituciones más exitosas (por número de presencia y efectividad) de los Andes prehispánicos.

Así, en éstas investigaciones se reconoce que los tambos fueron instituciones que estuvieron dirigidas por una administración jerárquica, la cual fue más compleja de lo que comúnmente ha sido aceptada y sugerida (Hyslop 1984). A su vez, se sugiere que los tambos estuvieron inmersos bajo varios niveles de supervisión y administración imperial; a la vez que empleó líderes y pobladores locales para su efectivo funcionamiento; aspectos que también han sido desarrollados en trabajos anteriores (ver Chacaltana 2010).

Finalmente, se propone que el estudio de los tambos trae consigo varias ventajas teóricas en

2 En algunas provincias donde el poder imperial no fue administrativo ni de orden directo, existen sutiles diferencias en los tipos de controles ejercidos por el imperio Inca. Esto trajo como consecuencia que se pensará que el impacto local fue mínimo y poco complejo; pero la influencia imperial puede ser categorizada a través del impacto local de la infraestructura imperial, del orden burocrático, institucional, u de la administración de la mano de obra, de la transformación del paisaje agrícola entre otras variables. el estudio de los imperios prehispánicos. En primer lugar, conociendo que uno de los mayores problemas en los estudios de los imperios antiguos es enfrentar la escala (Sinopoli 2001:447), y sabiendo que los tambos fueron instituciones de pequeña escala y las instituciones más numerosas de los Andes; aquí sugiero que una de las maneras para enfrentar el problema de la escala en las investigaciones del imperio Inca puede enfocarse en los tambos, y en segundo lugar, desde mi punto de vista, es a través de instituciones como los tambos, es decir, de instituciones de escala pequeña, que el dinamismo y la heterogeneidad de la administración Inca en las provincias, y en casos locales, pueden ser observados, y los tambos son ideales para realizar estudios de abajo para arriba (bottom-up studies) ${ }^{3}$.

\section{Presencia Inca en el Colesuyo, Y EN El VAlle alto de MoQuegua}

El Colesuyo fue una subdivisión territorial del Collasuyo (Barriga 1955:116; Cúneo Vidal 1915:145; Julien 1991; Pärssinnen 1992, 2003:224; Trelles Arestegui 1991) que fue reconocida por Maria Rowstorowski (1986) a través de los estudios de los documentos históricos. Existen discusiones de lo que realmente representó el Colesuyo y de cuando fue institucionalizado; pero en general, se sugiere que el Colesuyo fue una unidad territorial, reconocida durante la época colonial (Julien 1979, 1985, 1987) y que comprendía el valle alto, el valle medio, y la costa desde los valles de Tambo en Arequipa hasta el valle de Azapa en el extremo norte de Chile (Julien 1985, 1991; Rowstorowski 1986), siendo el valle de Osmore la capital política del Colesuyo durante la época colonial, y probablemente durante la época Inca (Rowstorowski 1986) (Fig. 1).

Los documentos históricos indican que varios pobladores altiplánicos viajaban a esta zona para obtener recursos del valle, especialmente maíz y ají; y pescado y cochayuyo de la costa del Pacífico (Diez de San Miguel 1964 [1567]). Asimismo, estos documentos también sugieren que durante la época Inca existían varias colo-

3 Ver Carla Sinopoli (2001). 


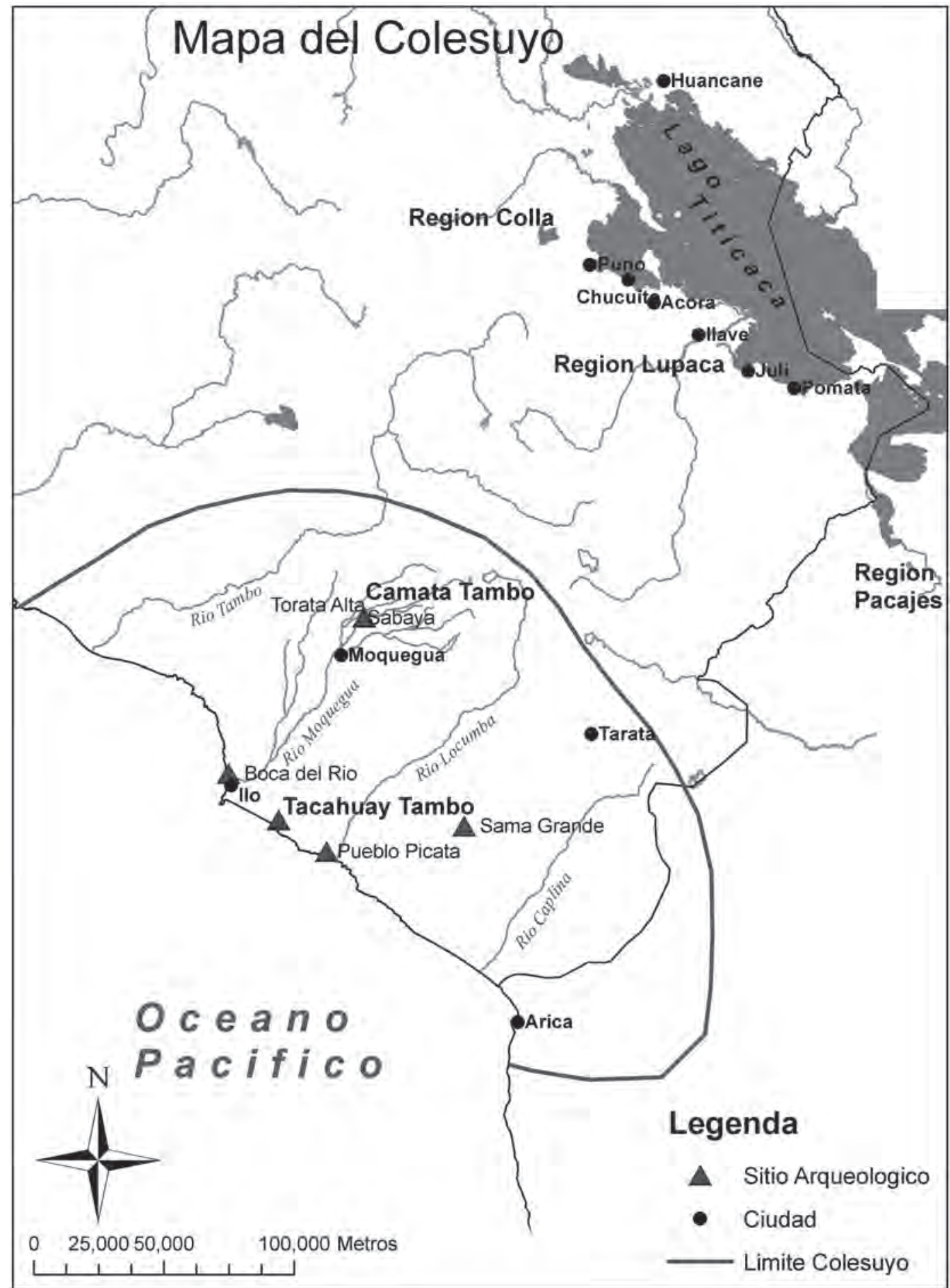

Figura 1: Mapa tentativo del Colesuyo mostrando algunos sitios incas importantes del valle de Moquegua y del altiplano. 
nias de diferentes grupos étnicos del altiplano explotando los recursos económicos del valle. Por otro lado, en base a datos etnohistóricos como arqueológicos (Reycraft 1998) sabemos que estas interacciones se caracterizaron por ser fluidas a través del tiempo, múltiples, de varios niveles y, estar estructuradas por las sociedades que las promovieron o las crearon (Chacaltana et al. 2010; Van Buren 1996).

\section{Los fragmentados Estuquiña del Intermedio Tardio}

Durante el Intermedio Tardío el valle alto y medio de Moquegua estuvo habitado por los Estuquiña. Los Estuquiña tuvieron un desarrollo cultural formado por pequeños grupos fragmentados, con una estratificación social de dos niveles formados por comunes y líderes y fueron grupos heterárquicos debido a que no se ha notado una jerarquía entre los asentamientos del valle de Moquegua durante este periodo (Moseley 2001; Williams 1997). El patrón de asentamiento de estos grupos se caracteriza por estar localizados y separados unos del otro, ya que los pueblos se ubican en la cima de los cerros del valle y estan rodeados por muros de protección, sugiriendo que estaban inmersos en constantes enfrentamientos endémicos (Stanish 1989). Estos grupos tuvieron una economía agrícola de pequeña escala, sus terrazas agrícolas al lado de sus asentamientos domésticos, y tuvo una economía dirigida al consumo doméstico. Es interesante observar de que a pesar de no haber evidencias de almacenamiento a nivel comunal, se ha sugerido e incluso aceptado que los Estuquiña tenían excedentes, ya que existía un intercambio con los grupos del altiplano ubicados hacia el Este del Colesuyo (Stanish 1997).

Es así que la transformación de la economía local durante la ocupación Inca del Colesuyo en los valles de la zona sur, es un tema aún poco entendido por los investigadores (Bürgi 1993; Llagostera 1976; Muñoz y Chacama 2006). Algunos investigadores sugieren que la ocupación Inca en los valles de los Andes sur-centrales fue mínima, y que el imperio utilizó las mismas instituciones de control y administración que las poblaciones preincas (Llagostera 1976). Al contrario, otros investigadores sugieren que durante el Intermedio Tardío, periodo anterior a la ocupación Inca, el valle de Moquegua tuvo interacciones esporádicas, flexibles, y no institucionalizadas con las poblaciones altiplánicas; interacciones que fueron formalizadas e institucionalizadas durante la presencia imperial en el valle (Stanish 1991, 1992). Estas dos posiciones tienen en común que no explican de qué manera se utilizó o se impusó el control imperial en la zona, tampoco sugieren la manera que se articularon con las sociedades locales, y ni explican cómo se transformó la economía política y la dinámica cultural local bajo presencia imperial.

Por otro lado, las sociedades desarrolladas en el altiplano como los Colla y los Lupaca, ubicadas al Norte y al Noroeste del Lago Titicaca respectivamente, fueron complejos y poderosos grupos altiplánicos que ejercieron algún tipo de control sobre los recursos del valle. Por otro lado, uno de los motivos por los cuales no se entiende la naturaleza y la manera cómo fueron transformadas las interacciones entre el Colesuyo y el altiplano durante la época Inca, y a nivel de la comunidad, es debido a que existe poca densidad de materiales y arquitectura Inca en el valle medio, alto, y bajo. Esta característica ha sido interpretada como una leve y baja inversión imperial en el valle (gobierno indirecto, área marginal, etc.); posición que no toma en cuenta otro tipo de evidencias importantes como la intensificación agrícola (construcción de terrazas, canales, y reservorios); presencia de sitios administrativos como Sabaya a menos de $5 \mathrm{~km}$ de Camata Tambo, del mismo Camata Tambo; y la administración y burocracia imperial que requerió la organización de los trabajos agrícolas de transporte y de almacenamiento. Asimismo, estas posiciones provienen de un marco teórico centro-periferia, donde se observa al centro como agente innovador y desde donde provienen todos los cambios y decisiones políticas, y como consecuencia, se observa a la periferia como pasiva y receptora (Stein 2002a, 2002b), por lo que la región del Colesuyo fue categorizada como pasiva y carente de cambio. Es así que en este trabajo observamos el Colesuyo desde una perspectiva desde abajohacia arriba, es decir, vemos la manera cómo esta 
región, y una comunidad local, fue afectada por la presencia y políticas imperiales, cualquiera haya sido su naturaleza.

\section{SistemAS DE ALMACENAMIENTO}

Los sistemas de almacenamiento centralizado fue una estrategia económica incaica que apareció de manera significativa en varias regiones de los Andes, y por varias razones (LeVine 1992; Watchel 1982). Estos almacenes centralizados mayormente se observan en los sitios administrativos imperiales, pero también se pueden ver en otros sitios como en tambos y zonas de acopio (D’Altroy y Hastorf 1992; Hyslop 1984). En el Colesuyo los sistemas de almacenamiento centralizado se desarrollaron de manera significativa en el valle alto de Moquegua y durante la presencia imperial ${ }^{4}$. Camata Tambo presenta 31 qollqas o cuartos de almacenamiento y una capacidad promedio de almacenamiento de aproximadamente $700 \mathrm{~m}^{3}$ (Stanish y Pritzker 1983), siendo el sitio con mayor número de cuartos de almacenamiento en comparación con otros sitios del valle, y del mismo Colesuyo. Asimismo, este sitio presenta una posición estratégica -entre la costa del Colesuyo, el valle alto y medio, y el altiplano (puna andina sobre los 3,500 msnm) - y está al lado de una innovadora e incrementada tecnología agrícola y un camino Inca, características que sugieren que este sitio cumplía otras funciones además de proveer de comida y alojamiento para los transeúntes oficiales.

En general, los sistemas de almacenamiento centralizados son una expresión material de control de un poder central sobre sobre la producción, distribución, y manejo de los productos agrícolas, de la mano de obra, y de un tipo de tecnología (Morris 1986; Smyth 1991). El im-

4 En Cerro Baúl, asentamiento Wari ubicado en el valle alto de Moquegua, se han encontrado cuartos de almacenamiento de dos pisos al lado de un palacio provincial, pero el sistema de almacenamiento Wari tiene caracteristicas diferentes como un número menor de cuartos, una tecnología menos sofisticada, y por estar dentro, y al lado de las zonas de elite (Williams 2006), características que se diferencian de los sistemas de almacenamiento incaicos. perio Inca empleó una alta tecnología de almacenamiento que le permitió acceder y controlar los productos en varios pisos ecológicos de los Andes, alcanzando un poder político y económico nunca antes visto en los Andes.

\section{Camata TAmbo}

Camata Tambo fue un edificio de forma rectangular de aproximadamente 120 × 50 m de ancho, ubicado en el valle alto de Moquegua a 2,800 msnm y a menos de $100 \mathrm{~m}$ de Camata Pueblo (Fig. 2), y sobre la cima de una colina a desnivel con la parte norte a mayor altura, y la zona sur a menor altura. Camata Tambo fue excavado en el 2006 por arqueólogos del Museo Contisuyo, Proyecto dirigido por la licenciada Mónika Barrionuevo bajo el nombre de Proyecto Arqueológico "Unidades Domésticas y Agrícolas en los valles de Chuquibamba, Arequipa y Torata, Moquegua" (PDAM). Este proyecto se realizó gracias a los fondos del Dr. Christopher Dayton, quien obtuvo una beca de la National Science Foundation No. BCS-0539037. Por otro lado, la autora de este artículo utilizó los fondos de la American Phylosophical Society de Philadelphia, beca de la Lewis and Clark Funds para los análisis de las muestras de polen. Estos análisis fueron realizados por el biólogo Luis Huamán de la Universidad Cayetano Heredia, y los análisis de los materiales botánicos macro fueron realizados por el Dr. David Goldstein y por la arqueóloga Lizzette Muñoz. Asimismo, este sitio fue excavado en 1990 por Nicolas Güillaume-Gentile (1992), arqueólogo fránces que realizó trabajos en las qollqas del tambo como del pueblo.

\section{Excavaciones y evidencias}

Considerando las dos investigaciones mencionadas, de las 31 qollqas rectangulares de Camata Tambo se han excavado un total de cinco (3 por el presente proyecto y 2 por Güillaume Gentile). Las qollqas de Camata Tambo se encuentran concentradas en tres sectores del sitio: sur, noroeste y noreste. El sector sur está compuesto por 7 qollqas, correspondientes a los almace- 


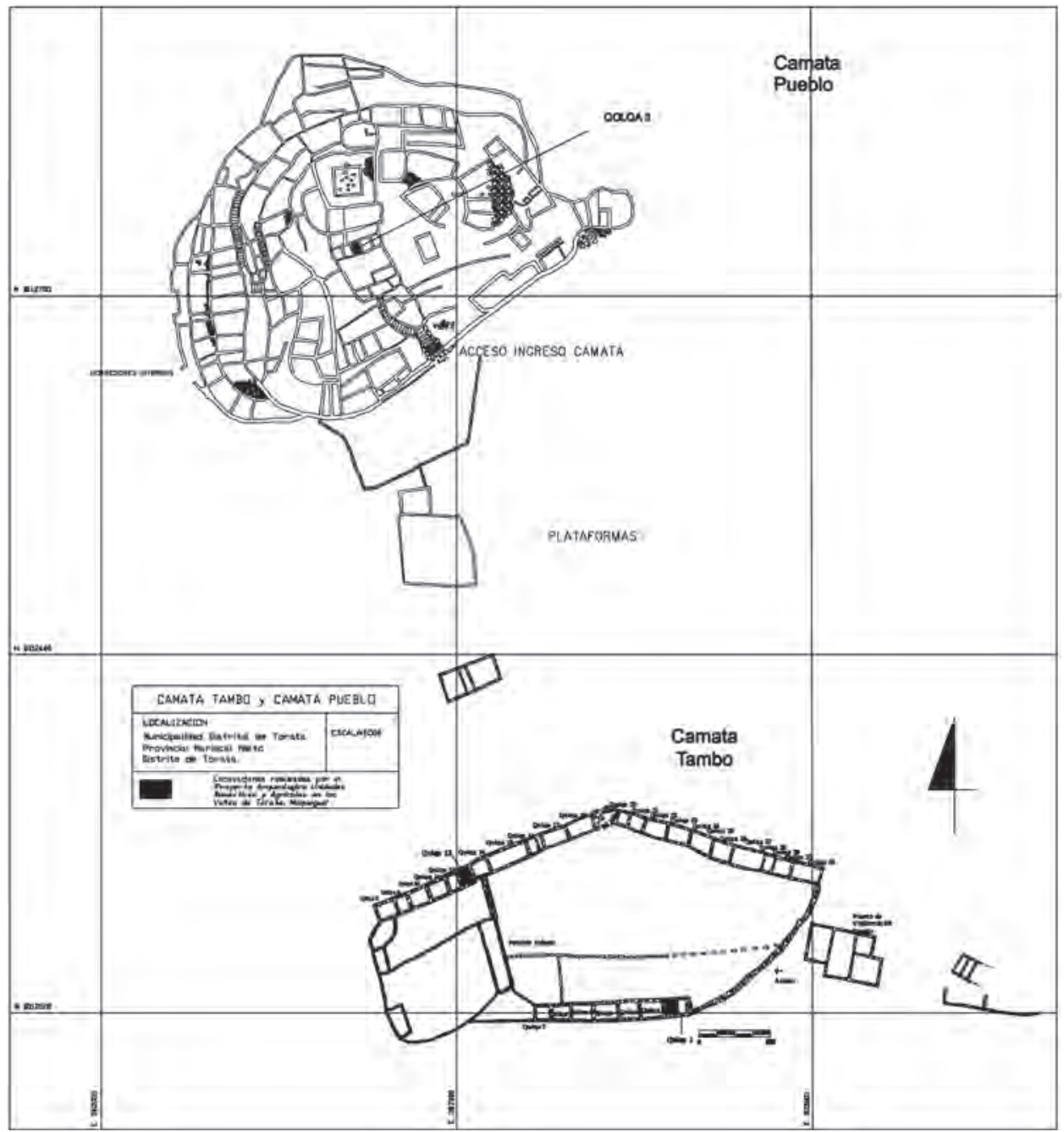

Figura 2: Mapa de Camata Tambo y Camata Pueblo mostrando las áreas excavadas por el Proyecto PDAM en el 2006

nes de mayor tamaño y de aproximadamente 6 x $5 \mathrm{~m}$. Las 11 qollqas del sector noroeste son de aproximadamente $5 \times 4 \mathrm{~m}$, mientras que las 13 qollqas del sector noreste, tienen aproximadamente $4 \times 3 \mathrm{~m}$. Estas últimas se encuentran bastante deterioradas, pero se observa una arquitectura variada en la zona interior.

Todas las qollqas presentan paredes de piedras rectangulares y tienen pequeñas ventanas en la parte de la fachada que mira hacia el interior del tambo. Al mismo tiempo, presentan piedras planas dipuestas de forma diagonal que sobresalen de las paredes. Estas lajas posiblemente funcionaron como escaleras para ingresar a los almacenes por la parte superior. Acá mencionaremos brevemente las excavaciones y los hallazgos paleobotánicos. Se hace notar que la pobre recuperación de los materiales orgánicos y cerámicos era predecible debido a prácticas particulares de almacenamiento incaicos y a procesos históricos regionales, por lo que se tomaron varias muestras para realizar análisis botánicos de polen y flotación. 


\section{QOLLQA 1}

La qollqa 1 tiene una dimensión de 5 × $6 \mathrm{~m}$, se encuentra en el extremo sureste del tambo, y es una de las qollqas mejor conservadas en comparación de las otras 30. Esta qollqa tiene una ventana pequeña de ventilación y escalones de acceso en la fachada exterior. Se excavó un total de 3 x 6 metros y se encontraron dos pisos con ocupaciones principales. En el piso 1, es decir, en el primer piso expuesto en las excavaciones, y el que se contruyó en el momento cercano al abandono de la qollqa, fue formado por una superficie de ocupación de barro y lajas; el cual se halló bastante disturbado por el colapso de los muros. Sobre este piso se clausuró la ventana de la qollqa con lajas paradas y argamasa, y por sobre estas lajas, se halló una ofrenda de camélido, de donde se tomó una muestra de Carbono 14 que tiene un fechado de 1485 - 1643 d.C. con 2 sigma de calibración, del cual hablaremos mas adelante. El piso 2, capa G, fue un piso de barro batido de color amarillento y de argamasa rojiza. A pesar de que presenta evidencia de ocupación, se hallaron pocos restos culturales. Bajo este piso se halló una superficie de lajas y

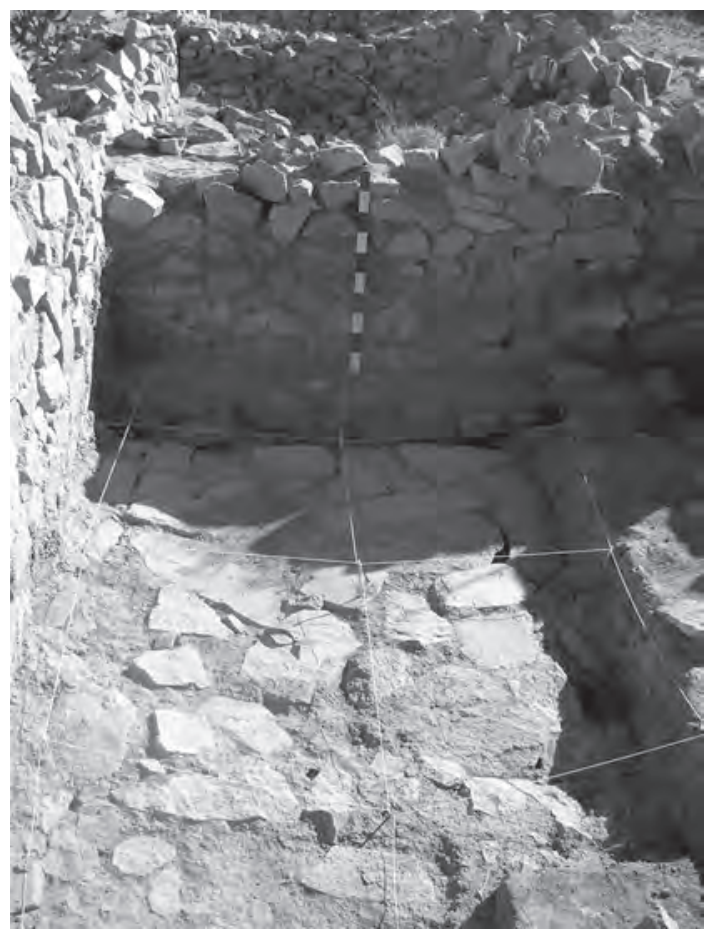

argamasa de barro. El piso de lajas estuvo dispuesto de manera horizontal y bastante bien conservado, sobre las cuales se puso la capa $G$ (barro batido) (Fig. 3). Bajo las lajas horizontales se encontró un primer relleno compuesto por piedras de tamaños mediano a grande $(20 \times 30 \times$ $30 \mathrm{~cm}$ ), combinadas con barro; y bajo este piso, se encontró un segundo relleno fundamentalmente compuesto de barro con escasas piedras de tamaño pequeño. Además, en esta qollqa se halló un ducto de ventilación de aproximadamente $30 \mathrm{~cm}$ de ancho que cruzaba la qollqa de norte a sur, y que no tenía ninguna salida hacia el exterior (Fig. 4). Al interior de la qollqa, se encontró muy pocos restos orgánicos, siendo los más destacados algunos restos de erizos de mar (Loxechinus albus) y otros moluscos no identificados, y que se concentran en mayores cantidades en la capa D y E, es decir en el Piso 1 (Goldstein y Muñoz 2007).

\section{Información Botánica}

Según la información obtenida de los análisis de polen y flotación recogidos de esta qollqa se sugiere que tuvo diferentes productos almacenados durante las dos ocupaciones de usos. Los análisis de polen en las capas F, G y H, es decir las capas mas tempranas, encontramos abundante vestigios de molle (Schinus molle), Chenopodium/Amaranthus, y Zea mayz. En los pisos D y E de la qollqa también hallamos presencia de Zea mayz, de molle, pero también de Solanum/Lycopersicon en donde están representados la papa, el tomate andino, y el pepino. Por otro lado, las muestras de flotación en seco arrojaron evidencias de papa (Solanum tuberosum), que también se encuentran en las muestras de polen obtenidas de las terrazas agrícolas de los alrededores (Solanum/Lycopersicon).

En general, en las muestras de flotación encontramos poca cantidad de maíz lo que podría estar reflejando prácticas de almacenamiento. Morris comenta que en las qollqas de otros sitios Incas el maíz se almacenaba dentro de vasijas de cerámica (Morris 1992), por lo que los restos en el piso de estas estructuras son casi nulos.

Figura 3: Foto del piso de la Qollqa 1, Camata Tambo 


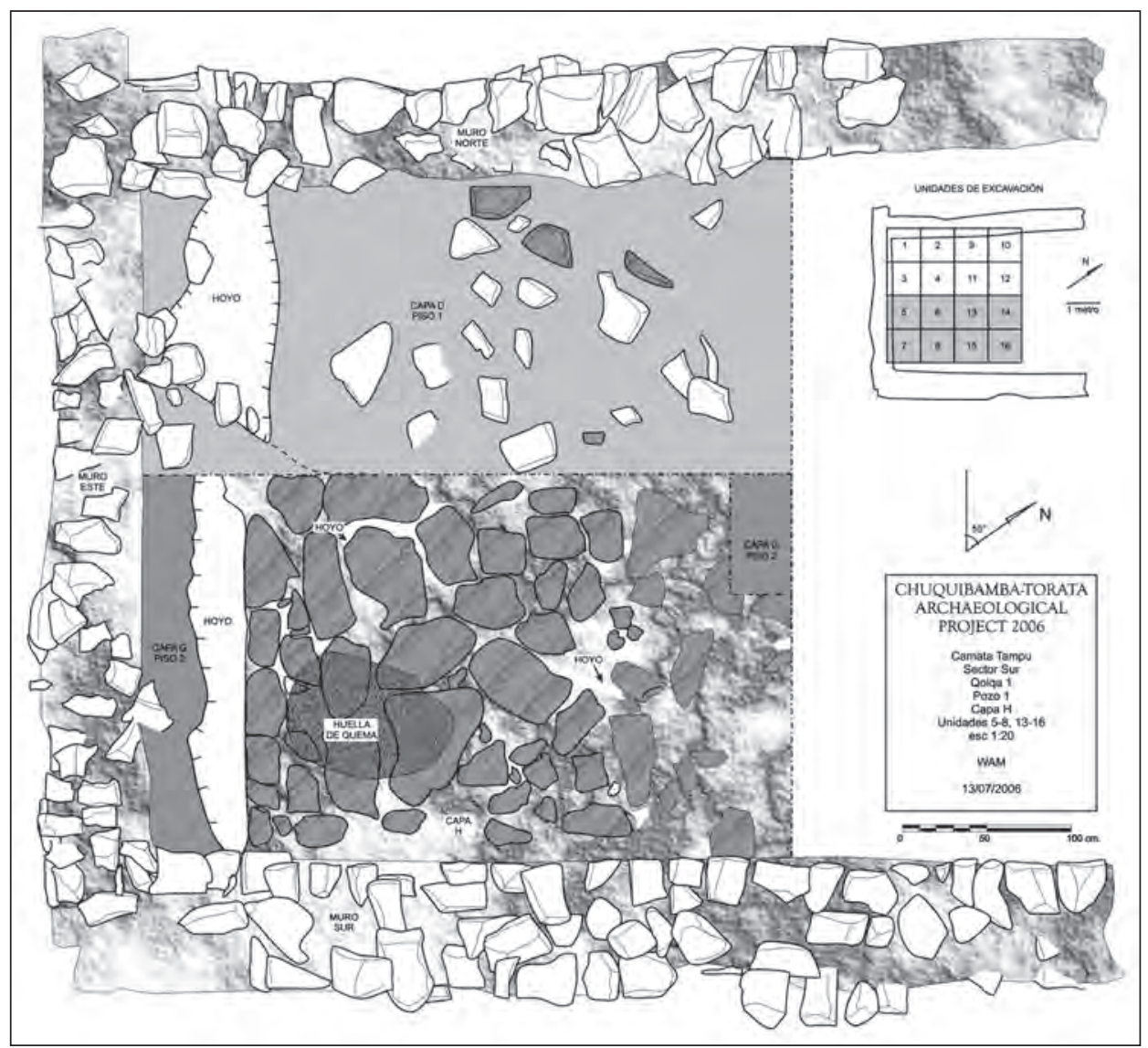

Figura 4: Dibujo en planta de la qollqa 1 de Camata Tambo, mostrando el piso de lajas y el canal de ventilación que corre la estructura de norte a sur.

Por otro lado, también es importante mencionar que el grano de maíz encontrado se halló seco, al igual que en los otros sectores del tambo y del pueblo. Se guarda seco el maíz cuando es consumido para comida y, para ser almacenado por largos periodos de tiempo. Así mismo, también se puede preparar chicha de jora con este tipo de maíz (comunicación personal, David Goldstein 2009). Por otro lado, los análisis macrobotánicos detectaron ají (Capsicum sp.) en esta qollqa. Es importante mencionar que no se encuentra polen de ají en esta qollqa, ni restos macrobotánicos de Capsicum sp. en las otras qollqas del Tambo, ni en las zonas agrícolas de los alrededores; por lo que se sugiere que este producto pudo provenir de las zonas mas bajas del valle de Moquegua (medio o zona costera) donde si se halla ají (ver Goldstein 2005).
En resúmen, la qollqa 1 es bastante interesante porque se puede observar presencia de varios cultígenos económicos como Chenopodium/Amaranthus, Zea mayz, Solanum/Lycopersicon (por los datos macrobotánicos sugerimos que papa), Phaseleous (frejol), pero también fue una estructura donde se almacenó productos foráneos o regionales como productos marinos de la costa y ají del valle medio y bajo (ya que no hallamos polen de ají en los contextos agrícolas). Por otro lado, esta qollqa 1 presentó una tecnología de almacenamiento bastante sofisticada y diferente que no ha sido observada anteriormente en otras qollqas Incas. En este caso es el ducto de ventilación cerrado que fue una estructura especialmente diseñada para almacenar productos específicos, como productos foráneos (o regionales ya que estan dentro del Colesuyo) entre ellos los marinos y el ají, y maíz. 


\begin{tabular}{|c|c|c|c|c|c|c|c|c|c|c|c|c|c|c|c|}
\hline Polen & Capa & & & tivos & ecor & mic & & & Cañas & & ade & & $\begin{array}{r}\mathrm{No} \\
\text { tic }\end{array}$ & $\begin{array}{l}\text { nes- } \\
\text { os }\end{array}$ & Indet. \\
\hline & & 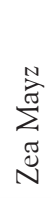 & 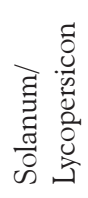 & 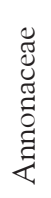 & $\begin{array}{l}\overrightarrow{0} \\
\stackrel{0}{0} \\
\sum_{\Sigma}^{\pi}\end{array}$ & 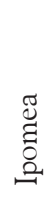 & 芞 & 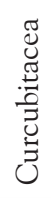 & & 号 & 莺 & 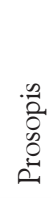 & 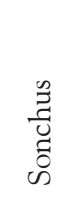 & 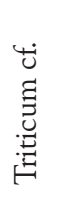 & 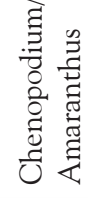 \\
\hline 146 & $\mathrm{C}$ & 0 & 0 & & & & & & & 0 & & & & & 0 \\
\hline 145 & $\mathrm{C}$ & 0 & 0 & & & & & & & 0 & & & & 1 & 0 \\
\hline 149 & D (Piso 1) & 11 & 0 & & & & & & & 11 & & & & & 0 \\
\hline 148 & D (Piso 1) & 12 & 7 & & & & & 2 & & 28 & 2 & & & & 0 \\
\hline 151 & $\mathrm{E}$ & 0 & 1 & & & & & & & 0 & & & & & 1 \\
\hline 147 & $\mathrm{E}$ & 5 & 0 & & & & & & & 16 & & & & & 6 \\
\hline 104 & G (Piso 2) & 6 & 6 & & & & & & & 0 & & & & & 8 \\
\hline 150 & $\mathrm{H}$ & 0 & 0 & & & & & & & 0 & & & & & 0 \\
\hline
\end{tabular}

Cuadro 1. Cuadro mostrando los polénes de los principales cultígenos de la Qollqa 1 de Camata Tambo.

\section{Discusión sobre los fechados radiocarbónicos}

A partir de las excavaciones y los análisis paleobotánicos que hemos descrito, se infiere que esta qollqa tuvo dos superficies de uso. La capa $G$ tiene una datación de 1392 - 1449 d.C. con 2 sigma de calibración utilizando el método sugerido por McCormac y colegas (2004) con la curva de calibración del hemisferio Sur (Dayton 2008:197-198), y las capas D y E que están asociados al último uso, y con un fechado AMS de 1485-1643 d.C. también con 2 sigmas. La fecha más temprana está confirmada por otra datación correspondiente a 10 semillas carbonizadas encontradas en la capa $\mathrm{H}$, que arrojaron un fechado de 1392-1448 d.C. con 2 sigmas. Es importante mencionar que aunque estos fechados son consistentes, uno de ellos corresponde al tronco que sostenía el ducto de ventilación. El tronco de sauce pudo haber sido cortado algunos años o décadas antes a la construcción de los almacenes del tambo, pero a pesar de ello, las otras fechas confirmarían una época temprana para la sugerida ocupación Inca en el Valle de Moquegua. Peter Bürgi (1993) ha sugerido que la incorporación Inca del valle empezó alrededor del 1450 d.C., aunque el intercambio con grupos del Cuzco o grupos Incas ya ubicados en el altiplano, al parecer ocurrieron décadas anteriores a la ocupación Inca (Stanish 1992; Pärssinen y Siiriäinen 1997).
En este caso, lo interesante es que los fechados de la qollqa 1 estarían indicando que Camata Tambo fue una instalación que fue construída en épocas tempranas para las fechas comúnmente aceptadas para el Colesuyo, e incluso para el área de los Andes sur-centrales (veremos más adelante).

$\mathrm{Al}$ respecto, hay otros aspectos que deben tomarse en consideración, y es que por ejemplo Hyslop sugiere que los tambos fueron los primeros edificios construídos en territorios conquistados, que permitíeron la expansión y la consolidación de las zonas incorporadas. También sugiere que los tambos pudieron haber funcionado como instituciones desde donde se planeaba la construcción de los centros administrativos, y las estrategias de incorporación de los diversos territorios de los Andes, esto debido a que tenían cuartos de almacenamiento y estructuras en donde se podían hospedar los burócratas imperiales, y el ejército encargado de la incorporación imperial.

Por otro lado, los fechados más tardíos son muestras de carbón proveniente del Rasgo 2, que es la ofrenda encontrada sobre la clausura de la ventana de ventilación de la qollqa que tiene un fechado de 1485 - 1643 d. C. con 2 sigmas. Este fechado se encuentra localizado bajo la ceniza del volcán Huaynaputina que explotó en 1600 d. C. 
confirmando su rango de fechado absoluto. Así se sugiere que esta qollqa estuvo operativa desde mediados del siglo XV hasta luego de la conquista y ocupación española del valle de Moquegua (alrededor de 1540 d.C.). Se menciona además que Güillaume-Gentile en sus excavaciones en la estructura 11 de Camata Tambo encontró cerámica colonial, indicando que el tambo siguió siendo utilizado durante las primeras décadas de la colonia.

\section{QOLLQA 13}

La qollqa 13 está ubicada en la hilera noroeste del tambo (Fig. 2), presenta una forma cuadrangular y una dimensión de 4.5 × $3 \mathrm{~m}$. Se escogió esta qollqa debido a que se encuentra en buen estado de conservación entre todas las qollqas pequeñas de este sector del tambo. Por otro lado, tiene interesantes rasgos arquitectónicos como la ventana ubicada al interior y que da hacia la plaza principal, y además presenta otra ventana más pequeña que está en la parte inferior de la fachada (entrada de un pequeño canal). Además, esta qollqa tiene protuberancias de acceso o escaleras en la fachada del muro norte (que da hacia la plaza) y del muro sur (que da hacia el exterior del tambo), sugiriendo que el acceso a esta qollqa pudo haberse realizado tanto de la parte externa, como de la parte interna del tambo. En esta qollqa se ubicaron las unidades del $1 \mathrm{al} 8$, y las unidades 10 y 11 de 1 x $1 \mathrm{~m}$. La unidad 9 (de $3 \times 0.50 \mathrm{~m}$ de largo) fue ubicada a lo largo del muro exterior, donde se realizó un pequeño cateo que permitió entender los dos canales de irrigación que la cruzaban de norte a sur y que fueron ubicados tanto en la parte interna como en la parte externa.

En la excavación realizada en esta qollqa se ha encontrado un único piso de ocupación - Piso 1, Capa C, que está formado por una supeficie compacta, de textura arcillosa, de color marrón y de aproximadamente 1 a $2 \mathrm{~cm}$ de grosor. Asociado a este piso se encuentra el Rasgo 1, que corresponde a la ventana-ducto que da hacia el interior del tambo. Este piso se distingue porque tiene lajas a lo largo de los muros de la qollqa, y porque presenta barro batido en el centro de la misma (Fig. 4). Debajo de este piso se encuentra un relleno de guijarros, sin presencia de tierra ni argamasa. Es una capa de relleno para base de pisos que presentan todas las qollqas de este tambo, y que esta com- puesta de material especialmente escogido. Bajo este primera capa de relleno de guijarros, encontramos capa de piedras grandes (aproximadamente de $20 \times 30 \times 30 \mathrm{~cm}$ ) y sin presencia de tierra, y al igual que la anterior, es una capa de relleno para base de piso. Las piedras de esta capa fueron escogidas tratando que fueran del mismo tamaño. Finalmente, bajo esta capa y asociada a la capa C, hay dos ductos subterráneos que cruzan la qollqa de Norte a Sur (Fig. 4).

\section{Información Botánica}

A pesar de que en general se encontraron muy pocos restos macrobotánicos, los análisis macro sugieren que en esta qollqa se encontró Solanum sp. (papa), Amaranthus sp. (kiwicha), echinopsis, que es una frutita parecida a la tuna, y abundante presencia de restos de molle (Goldstein y Muñoz 2007: 3-4). Por otro lado, la información de los análisis de polen sugiere que hay presencia de Solanum/Lycopersicon, que es la familia que incluye la papa (Solanum tuberosum), tomate (Lycopersicon esculento), pepino (Solanum muricatum) y berenjena (Solanum melongena). Asimismo, se encontró Zea mays, molle, y Chenopodium/Amaranthus, de la misma familia de la quinoa, la kañiwa y la kiwicha. También existe Poacaeae y Ambrosia que son pólenes de plantas que crecen a lo largo de los canales de regadío.

A partir de éstas evidencias se puede inferir que en ésta qollqa, al igual que la Qollqa 1 descrita anteriormente y de las excavadas por GüillaumeGentile, se enfatizó el control de la temperatura utilizando pisos abiertos permitiendo el paso libre del aire. Pero que, a diferencia de la Qollqa 1 que básicamente utilizó un sólo canal de ventilación, la Qollqa 13 hizo este control a través de canales de agua. La presencia de estos canales de agua que sugieren un meticuloso control de la temperatura llevó a Dayton sugerir que este cuarto de almacenamiento era ideal para el mantenimiento de tubérculos frescos (2008:202). Asimismo, en el Proyecto de Huanuco Pampa, Morris sugiere que en algunas estructuras de almacenamiento de este centro administrativo, el agua a través de canales pudo haberse utilizado para enfriar las estructuras destinadas a almacenar este tipo de productos (Morris 1992: 250-251). En efecto, 
el control de la temperatura en esta qollqa puede estar indicando que estuvo destinada a conservar tubercúlos frescos, ya que la temperatura es uno de los principales factores que influye en el tubérculo para acelerar su periodo de deterioro del producto; y por ende, su periodo de dormancia (el periodo de brote natural) ${ }^{5}$, o para que se alargue el mismo para aumentar el tiempo de almacenamiento. Es así que en base de la información macrobotánica y microbotánica y a las técnicas de almacenamiento halladas, podemos sugerir que la qollqa 13 estuvo principalmente destinada a almacenar Solanum tuberosum, Zea mayz, Annonaceae, y Chenopodium/ Amaranthus; pero que además de frutales como el molle y la tuna.

Asimismo, en las dos qollqas excavadas por Güillaume-Gentile en la zona norte de Camata Tambo, se encontraron sistemas de drenaje similar

\begin{tabular}{|c|c|c|c|c|c|c|c|c|c|c|c|c|c|c|c|}
\hline Polen & Capa & & & ivo & ecor & $\operatorname{micc}$ & & & Cañas & & Tader & & $\begin{array}{r}\text { No } \\
\text { tic }\end{array}$ & $\begin{array}{l}\text { nes- } \\
\text { os }\end{array}$ & Indet. \\
\hline & & 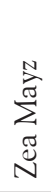 & 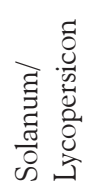 & 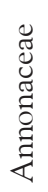 & 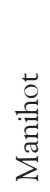 & 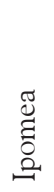 & 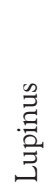 & 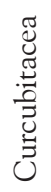 & & 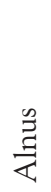 & 莺 & 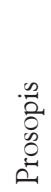 & 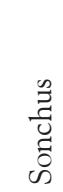 & 㤩 & 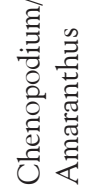 \\
\hline 175 & C (Piso 1) & & 1 & 1 & & & & & & & 1 & & & & 15 \\
\hline 178 & C (Piso 1) & 37 & & & & & & & & & & & & & \\
\hline 174 & C (Piso 1) & & 23 & 2 & & & & & & 14 & 1 & & & & \\
\hline 171 & C (Piso 1) & & & & & & & & & & & & & & \\
\hline 167 & C (Piso 1) & & 1 & & & & & & & & & & & & \\
\hline 169 & C (Piso 1) & 14 & 8 & & & & & & & & & & & & \\
\hline 170 & C (Piso 1) & & & & & & & & & & & & & & \\
\hline 173 & C (Piso 1) & & & & & & & & & & & & & & \\
\hline 176 & C (Piso 1) & & & & & & & & & & & & & & \\
\hline 168 & $\mathrm{~F}$ & 17 & & & & & & & & & 21 & & & & \\
\hline 177 & $\begin{array}{l}\text { G (Lajas } \\
\text { piso) }\end{array}$ & & & & & & & & & & & & & & \\
\hline 172 & $\begin{array}{l}\text { G (Lajas } \\
\text { piso) }\end{array}$ & & & & & & & & & & & & & & \\
\hline 106 & $\begin{array}{l}\text { G (Lajas } \\
\text { piso) }\end{array}$ & 6 & 13 & & & & & & & & & & & & 1 \\
\hline
\end{tabular}

Cuadro 2. Cuadro enseñando los polénes de los principales cultígenos de la Qollqa 13 de Camata Tambo.

5 Aunque el periodo de dormancia varia dependiendo de la variedad de la papa, usualmente este es de 1 a 2 meses, si el almacen no está expuesto a altas temperaturas (mayores de 10 grados centígrados), y si los cambios de temperatura no son drásticos (Werge 1977). Por otro lado, la dormacia se puede retardar si los tubérculos se mantienen en almacenes debajo de temperaturas de 2 a 5 grados centígrados de forma constante. a la qollqa 13 (1992). Esto podría estar indicando que como parte de la construcción del tambo, las qollqas ubicadas en el norte fueron diseñadas para dirigir y controlar el agua de las lluvias a través del tambo, y probablemente aprovecharon este desnivel natural de la colina para distribuir el agua por debajo de las qollqas con el fin de mejorar la temperatura y el almacenaje de las mismas. Y que ade- 


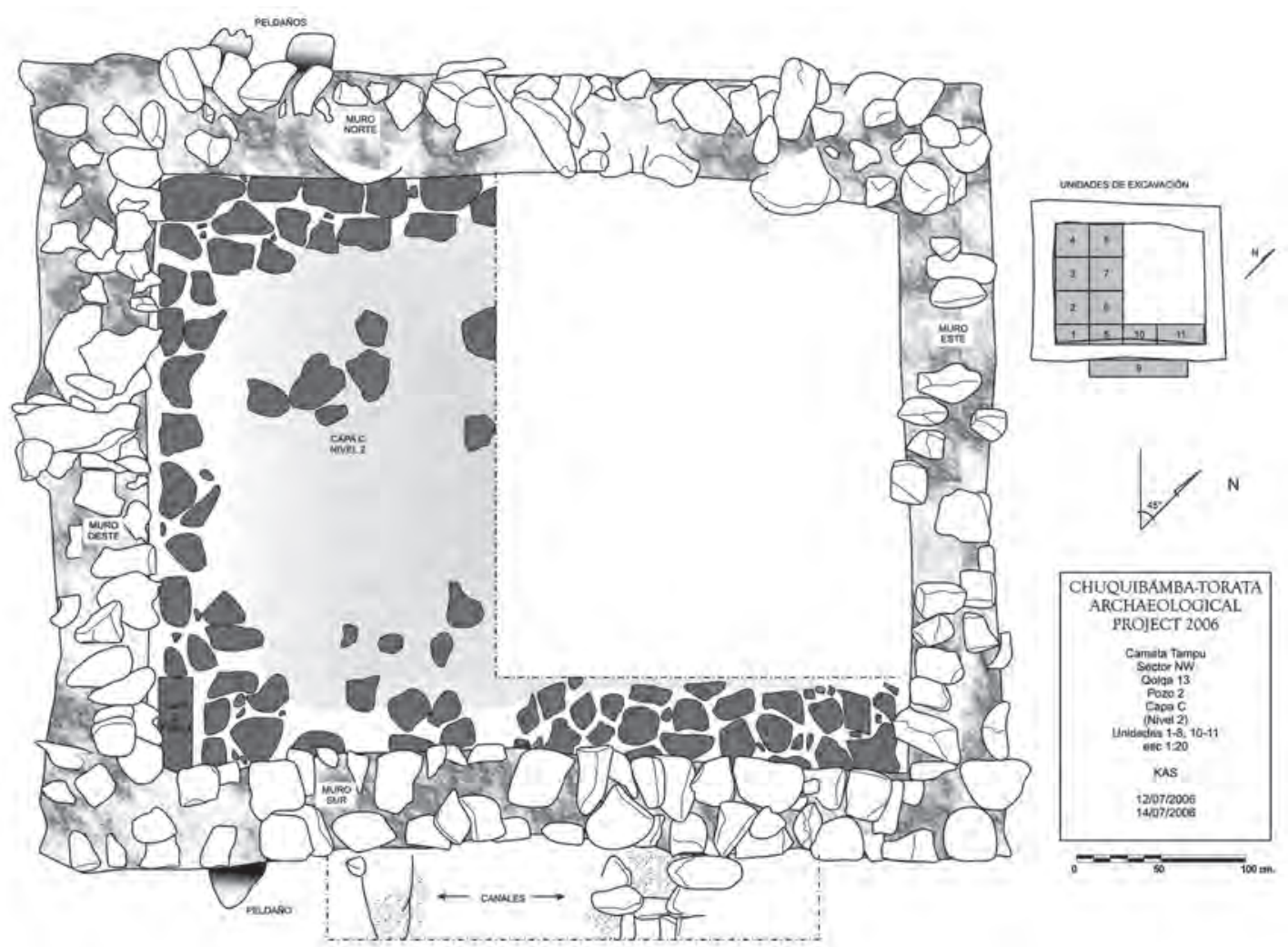

Figura 5: Dibujo de planta del piso de la qollqa 13 de Camata Tambo, mostrando detalle de los canales de agua que salen de la qollqa por el lado sur.

más, capaz esta zona se especializó en el almacenamiento de algunos productos como por ejemplo; la papa fresca e incluso el chuño, los cuales son productos que necesitan un control más estable de temperatura que otros productos como el maíz. Es importante notar que en esta qollqa fue evidente la casi nula presencia de cerámica, lo cual también podría estar hablando sobre el almacenamiento de algunos tipos de productos, como por ejemplo la papa que por lo general se almacena en sacos de ichu o de paja y sobre hojas.

\section{Complejo Chullpas}

Este complejo chullpas esta compuesto por cuatro cuartos rectangulares contiguos, y esta ubicado sobre una colina al Este de Camata Tambo, al lado de un sistema de terrazas agrícolas y dentro de un muro que encierra los cuartos y un grupo de chullpas. Este conjunto arquitectónico fue deno- minado como Complejo Chullpas por el PDAM (Barrionuevo et al. 2006; Dayton 2008).

\section{QOLLQA 3}

Debido a su buen estado de conservación, y para verificar si estas estructuras fueron de almacenamiento, excavamos en la tercera estructura rectangular. Además queríamos verificar si estas estructuras fueron contemporáneas, posteriores o anteriores a la ocupación Inca de Camata. La Qollqa 3 mide 5 x $5 \mathrm{~m} \mathrm{y}$, aunque no se realizaron fechados radiocarbónicos, Dayton (2008) piensa que éstas construcciones fueron hechas en épocas tardías de la ocupación Inca o durante la época colonial temprana (antes del 1600 d.C.). Esto debido a que el muro que rodea estos recintos presenta muros de construcción de diferente estílo que las qollqas del tambo, como 


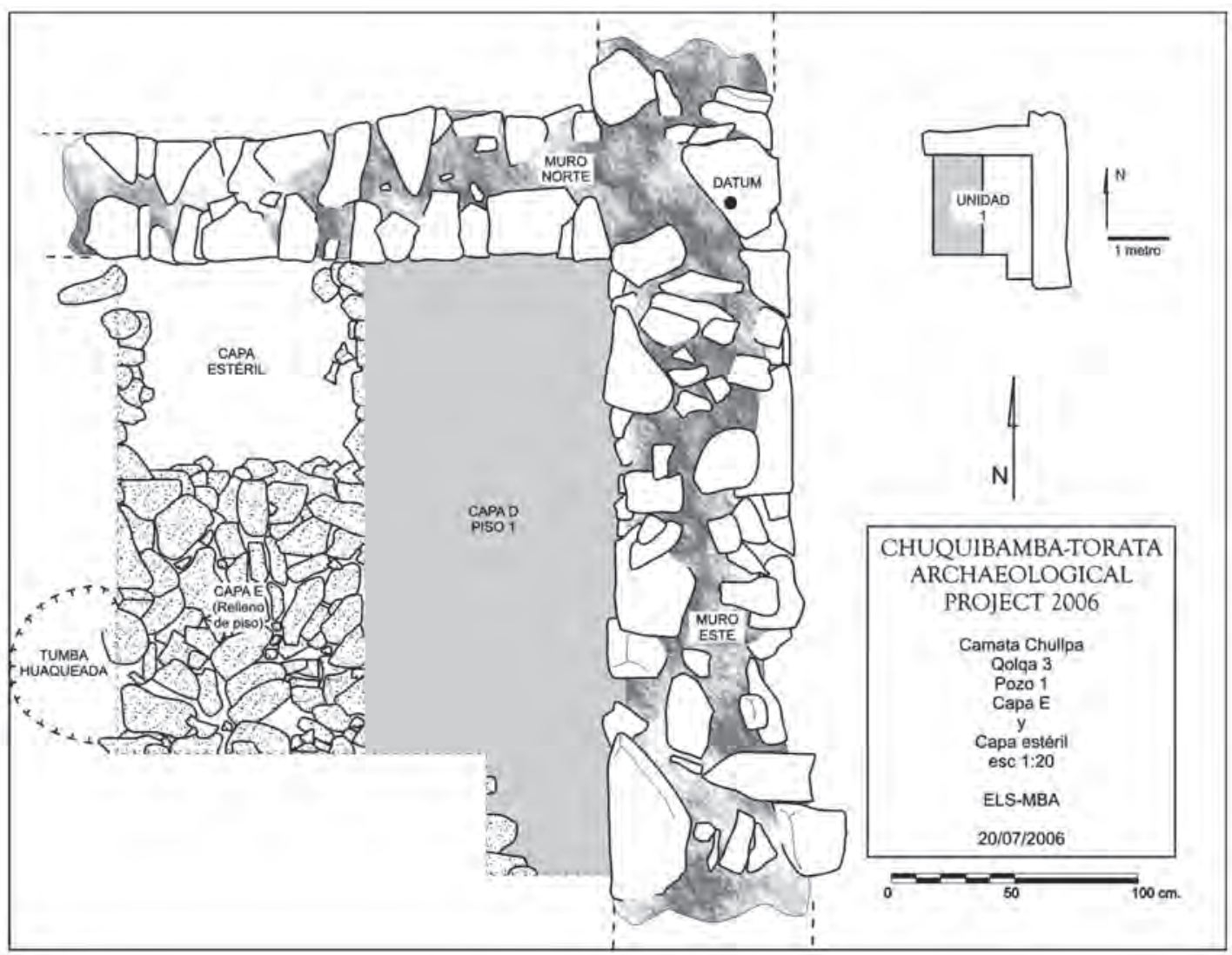

Figura 6: Dibujo en planta de la qollqa 3 de Camata Chullpas, mostrando detalle del Piso y el relleno de piedras bajo el mismo

piedras más pequeñas, y además, en los análisis de polen se identificó polénes de Triticum que es de donde proviene la familia del trigo, cultivo que llegó junto con los españoles. De esta manera excavamos una superficie de alrededor de 4 $\mathrm{m}^{3}$ en la esquina noreste de la estructura.

En las excavaciones, se halló un piso que corresponde a la capa $\mathrm{D}$, fue un piso de barro batido de aproximadamente $10 \times 15 \mathrm{~cm}$ de grosor (Fig. 5), y su superficie presenta un color beigegrisáceo. No se encontró gran cantidad de material cultural en esta qollqa, se ubicaron algunos fragmentos de carbón, y tiestos de cerámica burda y sin decoración. No se hallaron otros tipos de materiales culturales asociados y esta superficie esta asociada a la ventana pequeña que da hacia el muro sur. Bajo el piso se encuentra la Capa E que corresponde a un relleno compuesto de piedras angulares de tamaño consistente, y de dimensiones de $5 \times 10 \mathrm{~cm}$ y de $20 \times 30 \mathrm{~cm}$ y no había tierra o sedimento entre las piedras. Este es un relleno parecido a los encontrados en las qollqas 1 y 13 de Camata Tambo consttruido para la ventilación o control de la temperatura del ambiente (Figs. 5 y 6).

\section{Información Botánica}

Las muestras de polen realizadas en esta qollqa nos han otorgado información acerca de la continuidad de su uso durante la época colonial. A pesar de que no podemos afirmar si estas qollqas fueron construidas durante la época Inca o durante la época colonial (antes del 1600 d.C.), sí podemos sugerir que estuvieron siendo utilizadas cuando llegaron los cultivos del Nuevo Mundo 
al valle de Moquegua. Esto es interesante porque a pesar de que se ha sugerido de que uno de los sistemas indígenas que colapsó inmediatamente luego de la conquista de los Incas fueron las qollqas (Chacaltana 2009), debido a que este sistema funcionó bajo los conceptos de redistribución y reciprocidad económica que los Incas mantenían con los pueblos locales a lo largo del Tawantin- suyo; al parecer el sistema de almacenamiento de Camata Tambo continuó funcionando bajo un sistema colonial hispano durante los primeros años de la colonia.

Por otro lado, en las muestras macrobotánicas tomadas del piso de esta qollqa no se hallaron restos de cultivos económicos (sólo fragmentos

\begin{tabular}{|c|c|c|c|c|c|c|c|c|c|c|c|c|c|c|c|}
\hline \multirow[t]{2}{*}{ Polen } & \multirow[t]{2}{*}{ Capa } & \multicolumn{7}{|c|}{ Cultivos económicos } & & \multicolumn{3}{|c|}{ Maderas } & \multirow{2}{*}{\multicolumn{2}{|c|}{ 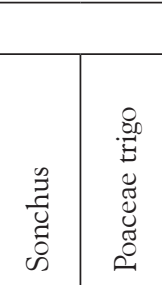 }} & \multirow{2}{*}{ 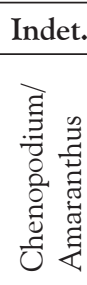 } \\
\hline & & 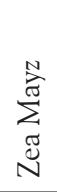 & 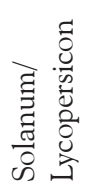 & 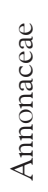 & 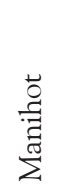 & 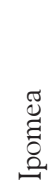 & 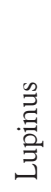 & 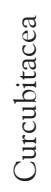 & $\stackrel{\mathscr{0}}{\leftrightarrows}$ & $\frac{\mathscr{g}}{\Xi}$ & 节 & $\begin{array}{l}n \\
0 \\
0 \\
0 \\
0 \\
0 \\
0\end{array}$ & & & \\
\hline 118 & D (Piso 1) & 3 & 17 & 1 & & & & & 1 & & 2 & & 1 & & 1 \\
\hline 117 & D (Piso 1) & 0 & & & & & & & & 7 & & & & 5 & 5 \\
\hline 116 & D (Piso 1) & 13 & 19 & & & & & & 1 & & 14 & & & 36 & \\
\hline
\end{tabular}

Cuadro 3. Cuadro mostrando los polénes de los principales cultígenos de la Qollqa 3, Complejo Chullpas de Camata Tambo

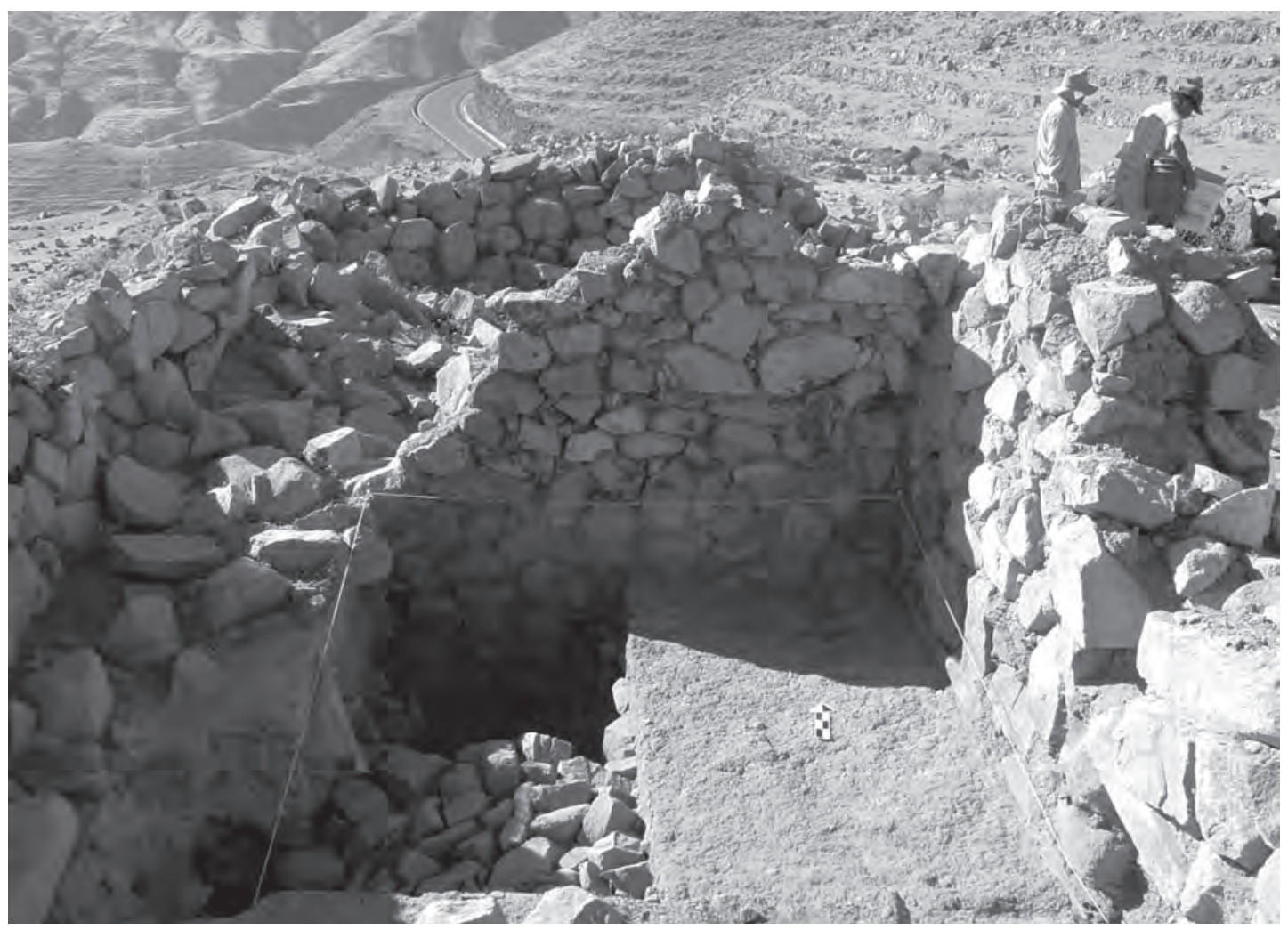

Figura 7: Foto de la qollqa 3 de Camata Chullpas, mostrando el piso de barro batido y el relleno bajo el mismo. 
de molle), pero sí se encontraron fragmentos de hierbas como la Malva sp., así como abundante presencia de excremento de roedores. A diferencia de las otras estructuras excavadas en el tambo en la qollqa 3 del complejo chullpas, se encontró una alta presencia de fragmentos de carbón de madera tanto inmadura como madura (Goldstein y Muñoz 2007). Por otro lado, los análisis de polen permitieron identificar los siguientes cultígenos, Annonaceae (chirimoya o guanabana), Chenopodium/Amaranthus (que podría ser también quinoa silvestre), Inga (pacae o huaba), Physalis (capuli), Solanum/Lycopersicon, Schinus molle y Zea mays (Huaman 2009: 35, Cuadro 3). De esta manera, se sugiere que probablemente esta qollqa estuvo almacenando cultivos similares a las qollqas del tambo, aunque capaz tuvo una mayor diversidad.

\section{Camata Pueblo}

Asimismo, Camata Pueblo que es el asentamiento Estuquiña adyacente a Camata Tambo (a 150 $\mathrm{m}$ de distancia), presenta evidencias de haber ido adquiriendo mayor acceso a tecnologías de almacenamiento incaicas. Esto es bastante interesante de observar porque habría permitido a la elite Estuquiña de Camata Pueblo, tener un mejor manejo y un mayor almacenamiento del excedente agrario local, con lo que los líderes locales de Camata aumentaron sus capacidades políticas y económicas y, probablemente, por primera vez, tuvieron un poder interregional estable que permitió a estas poblaciones asociadas al imperio distinguirse de los otros poblados Estuquiña (para otros ejemplos ver Spencer 1994), con lo cual, la dinámica política interna habría cambiado a ser una de mayor complejidad y basada en jerarquías.

\section{QOLLQA 3}

La estructura escogida para ser excavada, se encuentra en el medio y centro del pueblo, y es el tercer cuarto que va en dirección oeste-este de un sistema de 5 cuartos contiguos que tienen el mismo tamaño. Estos cuartos se encuentran dentro de un conjunto arquitectónico que tiene un patio abierto hacia el lado Sur, y hacia el lado
Norte presenta dos estructuras rectangulares de aproximadamente $15 \times 5 \mathrm{~m}$, con divisiones internas que según Güillaume-Gentile (1992) funcionarón como cuartos de almacenamiento de una estructura doméstica.

La qollqa 3 es un recinto rectangular de aproximadamente $2.5 \times 3 \mathrm{~m}$, presenta una ventanita en el muro sur, muro que da hacia el patio principal, y está formado por paredes de piedra canteada de menor calidad que las presentadas en el tambo; pero de mejor calidad que otros recintos del Pueblo Estuquiña. Esta estructura tiene una capacidad máxima de $5.9 \mathrm{~m}^{2}$ por qollqa (Dayton 2008:189). Se excavó esta qollqa en su totalidad a través de cuadrículas de $1 \times 1 \mathrm{~m}$.

Se ha sugerido que esta qollqa tuvo varias superficies de uso, siendo la Capa D, la primera encontrada en las excavaciones que corresponde a un apisonado y la que está más cerca a la superficie. La capa F, también ha sido considerada como una superficie de uso y estuvo formada de piedras grandes y sueltas, compactadas y distribuidas de forma heterógenea. Por otro lado, la Capa G, que es una capa fina distribuida de manera homogénea de barro batido y compacta, tiene de 1 a $2 \mathrm{~cm}$ de ancho, y está asociada a la ventana pequeña que se encuentra en la pared sureste (Fig. 8). Esta capa fue un piso formal bastante bien preservado. En esta capa se encontró algunos fragmentos de cerámica, restos óseos y restos de carbón. La capa H está compuesta por lajas por donde se ubicó un piso de barro. A diferencia del piso de las qollqas de Camata Tambo, estas piedras tuvieron mortero compuesto de arenilla rojiza y cenicienta, diferente del mortero utilizado en los muros.

Asimismo, la Capa I fue una capa compactada y semi-compactada de color amarillento, aparentemente utilizada para rellenar una fundación de la qollqa. Esta capa se extiende por debajo de las lajas planas de la Capa $\mathrm{H}$ y las estructuras de los muros principales. Entre las capas I y J, exísten varios depósitos de ceniza, carbón, y huesos animales, incluyendo camélidos y pescados, además de maíz quemado y cerámica del Intermedio Tardío. La capa J, estuvo hecha de lajas de piedra sugiriendo que este espacio fue utilizado anteriormente como cuarto de almacenamiento (Fig. 8). Este espacio estuvo 


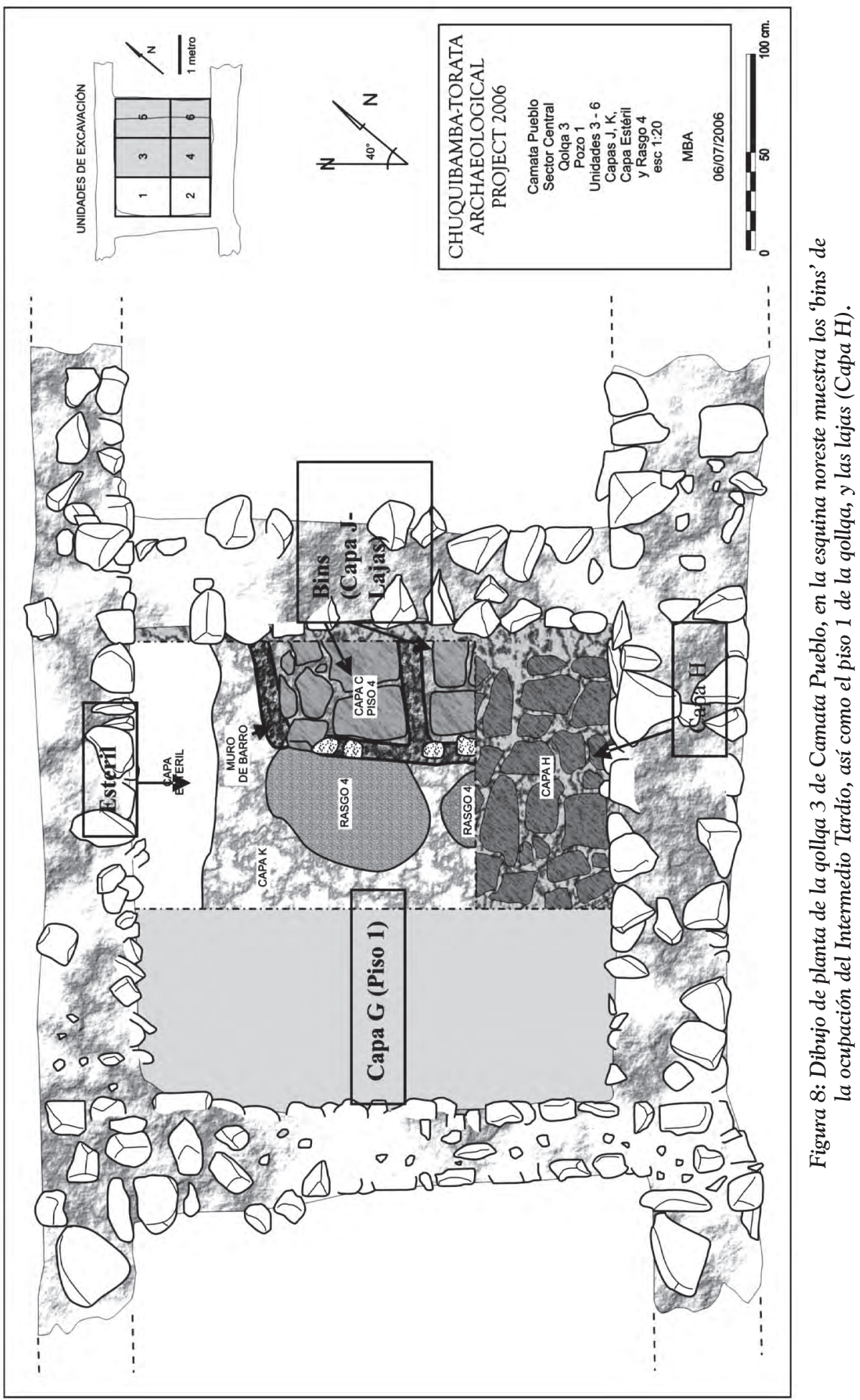


enteramente sellado y bien preservado por la Capa I. Además, se encontraron varios muros pequeños hechos de barro de 10 a $15 \mathrm{~cm}$ de grosor, que formaron dos pequeños cuartos que asemejan a los pequeños depósitos encontrados en las cocinas de las unidades domésticas de otros sitios Estuquiña excavados anteriormente o los llamados bins (Conrad 1993). En esta capa se encontraron varios fragmentos de cerámica del Período Intermedio Tardío de estílo Estuquiña y algunos fragmentos de estílo Gentilar que está asociado a la zona costera del Colesuyo (Covey 2000; Muñoz 1996, 1998). Esta capa está asociada a los Rasgos 3 y 4 que fueron dos fogones que estuvieron asociados a estas estructuras, pero se encontraron sobre, y al lado, de los mismos. Por otro lado, la Capa K corresponde a un piso de ocupación que presentó dos grandes fogones. De estos fogones se obtuvo muestras de carbono 14 (del Intermedio Tardío) de varias muestras de material botánico, carbón, óseo animal, y algunos fragmentos de cerámica. Estuvo formada por arcilla, arena, y gravilla distribuida de forma muy compacta, y corresponde a la arcilla que dispusieron sobre la capa estéril de la colina.

Rasgos 3 y 4: Basura de ceniza por debajo de la Capa I, tiene abundante material orgánico y se tomarón muestras para C-14. Al parecer esta basura fue quemada in situ debido a que presenta tres colores de quema, superior - gris oscuro, en el centro - rojo, y en la parte inferior - gris claro. Es de $40 \mathrm{~cm}$ de diámetro y de aproximadamente $25 \mathrm{~cm}$ de grosor. Por otro lado, el Rasgo 4 también esta por debajo de la capa I, y está formado por otro lente de ceniza y carbón que al parecer pudo haber sido esteras colocadas sobre el piso pero no se excavó el rasgo completo debido a que iba por debajo del muro. Es por ello que se desconoce las dimensiones totales de este rasgo, pero fue de aproximadamente unos $3 \mathrm{~cm}$ de grosor. Dentro de este rasgo se hallaron granos de maíz carbonizado y pequeños y medianos trozos de carbón.

\section{Discusión}

De esta manera, la excavación realizada en este espacio denotó aspectos interesantes sobre el impacto Inca en la economía de este pueblo Estuquiña. Los pequeños almacenes encontrados en las capas J, F y K, y los rasgos 3 y 4 asociados a estas capas, representan una ocupación anterior al uso y construcción de la qollqa. Excavaciones realizadas anteriormente por otros investigadores en otros sitios Estuquiña de la región como el mismo Camata Pueblo (Güillaume-Gentile 1992), San Antonio (Conrad 1993), Capanto (Bürgi 1993), y el sitio éponimo de Estuquiña (Conrad 1993), han encontrado recintos de almacenamiento similares dentro de las unidades domésticas, y más específicamente, dentro de la zona de cocina. Estos recintos de almacenamiento tienen forma rectangular de usualmente $0.5 \times 0.5 \mathrm{~m}$ y en ocasiones se han encontrado con restos de granos de maíz y carbón; y también se sugiere que fueron corrales de cuyes. Estas evidencias sugieren que estas pequeñas estructuras y/o bins excavados en este proyecto, sean pequeños cuartos de almacenamiento de función doméstica, al igual que los otros sitios Estuquiña.

Además, esta ocupación del Intermedio Tardío esta confirmada por las fechas AMS obtenidas de los lentes de quema encontrados y asociados a los pequeños recintos de almacenamiento. Los fechados C-14 sugieren que el carbón obtenido de la Capa I tuvo una fecha de 1294 - 1395 d.C. con 2 sigma de calibración. Se obtuvo una segunda muestra del Rasgo 3 que tuvo una fecha de 1299 - 1399 d.C. con 2 sigma de calibración (Dayton 2008). Estas dos fechas sugieren que, en efecto, estas estructuras fueron anteriores a la llegada de los Incas, es decir, durante el Intermedio Tardío.

Por otro lado, a pesar de que no se obtuvieron muestras de los pisos $\mathrm{G}$ y $\mathrm{H}$, que fueron los pisos de uso de este espacio como qollqa, se tomó una muestra de carbón del apisonado formado por sobre la capa G, es decir, de la Capa F. Este fechado fue de 1402 - 1460 d.C. con 2 sigma de calibración, sugiriendo una fecha similar a la del tambo. Es decir, que esta estructura se construyó 
en contemporaneidad con Camata Tambo, sitio Inca adyacente a Camata Pueblo.

\section{Información Botánica}

La información macrobotánica sugiere dos aspectos importantes, el primero es que un $80 \%$ del total de los restos botánicos recolectados de todos los restos hallados en este espacio provienen de las capas J, K, y L y de los rasgos asociados, es decir, del periodo del Intermedio Tardío. Por otro lado, la mayoría de los restos fueron recolectados de los hoyos de basura encontrados fuera de los cuartos de almacenamiento, y los mismos bins tuvieron poca evidencia de materiales macrobotánicos y de otra índole. Asimismo, también se han encontrado granos de maíz secos, grano de Chenopodium quinoa, y semillas de Phaseleous (frejoles). Al parecer los Rasgos 3 y 4 fueron hoyos donde se quemaron restos de producción de comida y/o corresponden a la concentración de los restos de cocina que fueron depositados en estos recintos. En los pisos F, G, y $\mathrm{H}$ que son superficies de cuando este espacio fue utilizado como qollqa no se hallaron restos macro-botánicos, sino más bien, algunos restos de óseos de roedores y fragmentos de carbón, pero en muy poca cantidad.

Por otro lado, los análisis de polen arrojan evidencias que complementan los datos sobre el uso de este espacio como zona doméstica antes de la ocupación Inca y, sugieren una lectura más clara sobre la transformación del consumo de plantas del Intermedio al Horizonte Tardío en este pueblo. Los análisis de polen tomados de las capas J y K, y de los rasgos asociados, presentaron abundante presencia de polen de Solanum/ Lycopersicon, Zea mays y casi nada de Chenopodium/Amaranthus. Estos datos son importantes ya que como se ha presentado en otros trabajos (Chacaltana 2010), en el valle de Torata, el Chenopodium/Amaranthus aparece con mucha mas intensidad en los sistemas agrícolas y en los contextos arqueológicos del Horizonte Tardío, y es nulo en las terrazas agrícolas del Intermedio Tardío (por ejemplo en Cerro Huayco que es una asentamiento del Intermedio Tardío Estuquiña) y en los contextos de Camata Pueblo.
Por ejemplo, los análisis macrobotánicos sólo encontraron en el Pueblo una semilla de quinoa sp. y esto fue en el Rasgo 3 (basura). Esto podría sugerir que existió una marcada intensificación de quinoa durante la presencia Inca en la zona de Camata (Goldstein 2005).

Así, entre las plantas no alimenticias se encontraron gran cantidad de polen de huarango (Acacia), sauce (Salix), y Sonchus, que son plantas que no se encontraron en momentos más tardíos (durante el Horizonte Tardío). Estas evidencias, según Huamán (2009:31), puede indicar un cambio ambiental, es decir, una sequía o un clima mas húmedo durante el Intermedio Tardío, y más seco durante el Horizonte Tardío. Por otro lado, a pesar de que se encontraron casi las mismas plantas en los pisos de la qollqa del Horizonte Tardío que en los bins del Intermedio Tardío como Basellaceae (posiblemente olluco) y Lauraceae (posiblemente palta); se halló jíquima (Pachyrhizus) en los contextos del Intermedio Tardío, pero en ningún contexto del Horizonte Tardío se ha encontrado este último cultígeno (Huamán 2009:31). La jíquima es un cultivo que hoy en día está desapareciendo debido a que compite con otros tubérculos, como por ejemplo, la papa, y el manihot (camote) más llamativos y preferidos por las algunas poblaciones; lo cual también pudo haber ocurrido durante la presencia Inca en la zona.

Algo interesante que ocurre en las muestras de polen de los pisos F, G y H que son los pisos de la qollqa, es que hay menos muestras de plantas silvestres con respecto a las muestras más antiguas (Huamán 2009: 31). Esto indicaría una mayor especialización de las actividades de almacenamiento, que probablemente va junto con una marcada intensificación de ciertas plantas económicas como por ejemplo: Zea mays, Chenopodium/Amaranthus, Schinus molle, y Solanum tuberosum, así como una mayor especialización agrícola (cuidado e intensificación) de los mismos cultivos a través del tiempo. Estas evidencias obtenidas de los cuartos de almacenamiento del Intermedio Tardío como de la época Inca en esta zona, y dentro de un contexto de almacenamiento del Pueblo Estuquiña, han sugerido que las poblaciones Estuquiña, y 


\begin{tabular}{|c|c|c|c|c|c|c|c|c|c|c|c|c|c|c|c|}
\hline Polen & Capa & & & tivos & econ & mico & & & Cañas & & lader & & $\begin{array}{l}\mathrm{No} \\
\text { tic }\end{array}$ & $\begin{array}{l}\text { nes- } \\
\text { os }\end{array}$ & Indet. \\
\hline & & 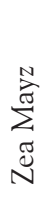 & 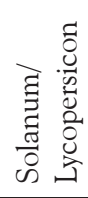 & 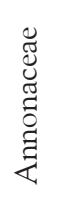 & 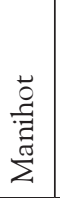 & 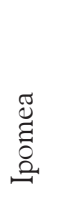 & 节 & 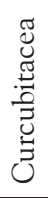 & 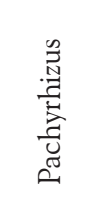 & $\stackrel{\varrho}{\Xi}$ & 㕦 & $\begin{array}{l}0 \\
0 \\
0 \\
0 \\
0 \\
0 \\
0 \\
0\end{array}$ & 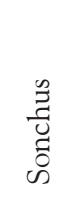 & 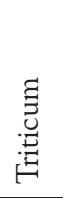 & 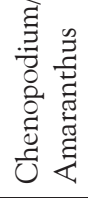 \\
\hline 159 & D (Piso 1) & 45 & 3 & & & & & & & & 12 & & & & \\
\hline 156 & D (Piso 1) & & & & & & & & & & & & & & \\
\hline 163 & D (Piso 1) & 29 & & & & & & & & & 13 & & & 11 & \\
\hline 161 & $\begin{array}{l}\text { E (Venta- } \\
\text { nita) }\end{array}$ & 49 & & & & & & & & & & & & & \\
\hline 153 & F (Piso 2) & 1 & & & & & & & & & & & & & \\
\hline 162 & F (Piso 2) & 1 & & & & & & & & & & & & & \\
\hline 158 & G (Piso 3) & 92 & & & & & & 3 & & & 4 & & & & \\
\hline 157 & G (Piso 3) & 54 & & & & & & & & & & & & & \\
\hline 160 & $\begin{array}{l}\text { G-H (La- } \\
\text { jas) }\end{array}$ & 31 & & & & & & & & & & & & & 14 \\
\hline 164 & G (Piso 3) & 36 & & & & & & & & & & & & & 6 \\
\hline 155 & G (Piso 3) & 69 & & & & & & & & & 19 & & & & 8 \\
\hline 165 & G (Piso 3) & 59 & 47 & & & & & & & & 2 & & & 3 & 5 \\
\hline 152 & $\mathrm{~J}$ (Piso 4) & 2 & & & & & & & & & & & 14 & & \\
\hline 105 & J (Piso 4) & 7 & 11 & & & & & & & & & & 4 & & 1 \\
\hline
\end{tabular}

Cuadro 4. Cuadro mostrando los polénes de los principales cultígenos de la Qollqa 3, de Camata Pueblo.

en especial las élites locales tuvieron un mayor acceso a ciertos productos intensificados durante la presencia Inca, como el maíz, la quinoa y la papa que son productos que también se observan en las qollqas de Camata Tambo.

\section{DISCUSIÓN SOBRE LOS FECHADOS radiocarbónicos de CAMATA TAMBo}

Los datos obtenidos en estas excavaciones son bastante importantes y significativos debido a que en la actualidad no existe un concenso de cuando fue incorporado el valle de Moquegua al imperio Inca. Por ejemplo, algunos investigadores aceptan la narración de Garcilaso de la Vega (1966 [1609]), quién relata que el emperador
Mayta Capac ${ }^{6}$, luego de conquistar la zona del altiplano mandó a un grupo de su ejército hacia la Costa, llegando a la provincia de Cuchuna [Cochuna] (nombre antiguo de las partes altas del valle de Moquegua), y realizando la conquista del Colesuyo a finales del siglo XV (alrededor de 1470-80) (Covey 2006). Según este cronista, cuando los Incas llegaron al valle, los grupos indígenas se refugiaron en la zona alta de una fortaleza que ha sido ubicada como Cerro Baúl. La estrategia militar incaica para hacer desistir a los nativos fue rodear Cerro Baúl, no permitiendo

6 Otras hipótesis comentan que durante épocas más tardías como en el reinado de Huayna Capac (finales del siglo XV) se conquistó el Colesuyo, y esto ocurrió a finales del siglo XV (Garcilaso de la Vega 1966 [1609]; Stanish 1998:105). 
el paso de los mismos, que luego de varios días tuvieron que rendirse debido a que no tenían la posibilidad de obtener agua ni comida. Así, el cronista continua relatando que luego de la conquista Inca del valle, el imperio fundó dos ciudades, una ubicada en las faldas del Cerro Baúl, que sería la moderna ciudad de Torata, y la otra en la parte media del valle, que sería la ciudad de Moquegua (Montenegro y Ubaldi 1906; Stanish 1998). Estos relatos sobre la expansión imperial fueron considerados como históricos por John Rowe, y fueron los que formaron la base para su famosa propuesta cronológica de 1946, en la que sugería que la conquista Inca del Colesuyo se realizó a finales del siglo XV.

Al mismo tiempo, basados también en relatos históricos hay hipótesis que sugieren que la conquista de la costa de los andes sur-centrales ocurrió en épocas más tempranas como durante los reinados del Inca Pachacútec (1438 - 1471) o Túpac Inca Yupanqui (1471-1493) (Betanzos 1987 [1557]: 119-121; Sarmiento de Gamboa (2007 [1572]); Pärsinnen 1992), es decir a principios del siglo XV. Por ejemplo, los cronistas Juan de Betanzos y Pedro Sarmiento de Gamboa escriben que luego de haber conquistado la zona del Contisuyo, Pachacútec ordenó a su hijo-guerrero Amaro Topa conquistar la franja costera del sur de Arequipa (para una mayor discusión ver Pärsinnen 1992:128). Estos datos sugieren que la conquista del Colesuyo se realizó décadas antes de lo que usualmente se acepta, y que la conquista de los Andes sur-centrales, en vez de haberse realizado desde la zona altiplánica, las huestes Incas vinieron de la zona costera sugiriendo que la conquista se realizó desde la costa hacia el altiplano.

De esta manera, los datos históricos sugieren dos posibilidades. La primera es que la zona costera de los andes sur-centrales fue ocupada por el imperio Inca durante fechas tardías, es decir, a finales del siglo XV, fecha que también es aceptada para otras zonas sureñas de los Andes como el noroeste Argentino y el extremo norte Chileno (Bárcena 1998; Bürgi 1993; Stanish 1998). La segunda posibilidad sugiere que estas conquistas pudieron haber ocurrido en épocas más tempranas, es decir, a principios del siglo XV, como también ha sido propuesto por otros investigadores como Terence D'Altroy y colegas (2000) (también ver Bárcena 1998, Stehberg 1991-1992), en base a sus fechados radiocarbónicos obtenidos en sus investigaciones en Argentina. En el Proyecto PDAM, y a diferencia de discusiones previas sobre la conquista Inca del Colesuyo, hemos obtenido fechados radiocarbónicos de las qollqas de Camata Tambo y del pueblo que sugieren que la conquista del imperio Inca al Colesuyo ocurrió a principios del siglo XV, y de los cuales ya hemos comentado un poco antes. Pero estos datos obtenidos en este proyecto son interesantes porque contribuyen de manera empírica a las discusiones sobre la presencia Inca en los Andes surcentrales.

\section{CONCLUSIÓN}

Las conclusiones de este trabajo han sido expuestas durante el mismo, pero de manera breve haré un resúmen de ellas:

Las élites Estuquiña comenzaron a tener un mayor poder económico y político dado por un más directo, y mayor acceso a los productos intensificados por los Incas, ya sea directamente de las zonas agrícolas, o a través del tambo. Este poder, además fue el resultado de una vinculación directa de las élites de Camata Pueblo con una institución imperial, como el Tambo. Es interesante notar que existen otros sitios Estuquiña como San Antonio (Conrad 1993), cercano a Torata Alta (sitio Inca - colonial) en donde podría haber pasado este mismo tipo de interacción entre poblaciones Estuquiña locales, y el estado Inca, presente a través de instituciones imperiales como Camata Tambo y Torata Alta.

Por otro lado, basado en estas evidencias sugiero que aunque la naturaleza de la presencia imperial en el Colesuyo representó una baja inversión financiera y administrativa por parte del imperio, el impacto económico y político locales fue alto y significativo. Esto debido a que las características de la poblaciones locales del Intermedio 
Tardío fueron de ser facciones competitivas y heterárquicas, con lo que la estratégia imperial en esta zona fue establecer y mantener relaciones íntimas con poblaciones locales específicas, e incluso con algunos líderes de estos grupos. Por otro lado, los beneficios encontrados a partir de esta interacción con los Incas habría sido una estrategia política que cada líder o poblaciones Estuquiña habrían buscado para sí misma.

Asimismo, las qollqas de Camata estuvieron almacenando productos regionales (productos marinos, ají del valle bajo, entre otros), y tuvieron una tecnología sofisticada especialmente diseñada para tales fines, asi como para almacenar grandes cantidades de productos que probablemente fueron trasladados a otras zonas alejadas, como por ejemplo a las emergentes sociedades del circum-titica (Collas y Lupacas).

Por otro lado, Camata Tambo cumplío tuvo funciones administrativas, económicas, y política, por lo que sugiero de que los tambos a través del Tawantinsuyo se expresaron física y funcionalmente de manera diferente (ver Chacaltana 2010). En general, los tambos se pueden definir por tres variables importantes: la primera y la más importante, es el interés imperial en la región, la segunda, son las múltiples características geográficas locales, y la tercera, las diferentes capacidades socio-políticas de las sociedades que habitaban la región. De esta manera, existieron edificios de arquitectura variada que tuvieron funciones de tambos como fueron los casos de Lambayeque (Conrad 1977; Helsley 1980; Netherly 1993) y Tarapacá (Aldulante del Solar 2001), es decir, que las funciones de tambo estuvieron integradas a construcciones anteriores, pero también hubieron tambos que se ajustaron a las definiciones tradicionales, y que cumplieron funciones administrativas, como los tambos de la puna que funcionaron para controlar los rebaños, o los tambos que servían logística e ideológicamente a la conquista e incorporación del Imperio (e.g. región de Azuay) (Hyslop 1984; Idrovo 1998: 72; Uhle 1969). En resúmen, existen vastas y dispersas tipos de tambos a través del Tawantinsuyo, pero se puede notar que los tambos fueron instituciones oportunistas y flexibles, y que se adaptaron a las necesidades imperiales, regionales y locales como lo fue Camata Tambo para el Colesuyo.

\section{Bibliografía}

Aldulante del Solar, Carlos

2001 "El Inka en Tarapaca y Atacama". En Tras la huella del Inka en Chile. C.y.L.C. Aldulante del Solar, ed. Pp. 18 - 73. Santiago, Chile: Museo Chileno de Arte de Colombino.

Bárcena, Roberto

1988 "Investigación de la dominación incaica en Mendoza. El tambo de Tambillos, la vialidad anexa y los altos cerros cercanos. Espacio, tiempo y forma". Serie I, Prehistoria 1:397-426.

1998 "El tambo real de Ranchillos, Mendoza, Argentina”. Xama 6-11:1-52.

Barriga, Víctor

1939 Documentos para la historia de Arequipa (1534 - 1558). Volume Tomo I. Arequipa: Editorial La Colmena.

Barrionuevo Alba, Monika; Robin Coleman; Sofía Chacaltana; Christopher Dayton

2006 Unidades domésticas y agrícolas en los valles de Chuquibamba, Arequipa y Torata, Moquegua. En Comisión Técnica Nacional de Arqueología, Instituto Nacional de Cultura. Lima.

Betanzos, Juan de

1996 [1576] Suma y narración de los incas [Narrative of the Incas]. Austin: University of Texas Press.

Bürgi, Peter

1993 The Inka Empire's expansion into the coastal cierra region west of lake Titicaca. University of Chicago.

Cañedo-Arguelles, Teresa

1993 "La organización del poder indígena en el Colesuyo (siglo XVI)". Revista Complutense de Historia de América No. 19:21-51. 
1994 "Cacicazgo y poder en el valle de Moquegua (siglos XVII y XVIII)". Archivo Arzobispal de Arequipa 1:17-30.

Chacaltana Cortez, Sofía

2009 From Inca tambos to tambarrias. Trabajo presentado en la conferencia 37th Annual meeting of the Midwest Andean Conference, Michigan University, Ann Arbor.

2010a El rol de los sistemas de almacenamiento de Camata Tambo y Camata Pueblo, un tambo Inca y una comunidad local adyacente ubicados en la región del Colesuyo, valle alto de Moquegua. Licenciatura, Pontificia Universidad Católica del Perú.

Chacaltana Cortez, Sofía; Christopher Dayton; Monika Barrionuevo

$2010 \mathrm{~b}$ "Coastal and highland storage systems of the Colesuyo, South Central Andes". Latin American Archaeology Publications, Pittsburgh University:147 $-168$.

Conrad, Geoffrey

1977 "Chiquitoy Viejo: An Inca administrative center in the Chicama Valley, Peru". Journal of Field Archaeology 4(1):1-18.

1993 "Domestic architecture of the Estuquina Phase: Estuquina and San Antonio". En Domestic architecture, ethnicity, and complementarity in the SouthCentral Andes. M. Aldenderfer, ed. Pp. 55-65. Iowa City: University of Iowa Press.

Covey, Alan

2000 "Inka administration of the Far South Coast of Peru". Latin American Antiquity II(2):119-138.

2006 "Intermediate elites in the Inka heartland". En Intermediate elites in Pre-Columbian States and Empires. C.a.A.C. Elson, ed. Pp. 112 -135. Tucson: The University of Arizona Press.
Cúneo Vidal, R.

1916 "Noticia historica del pueblo de Ilabaya en el departamento de Tacna". Revista histórica V(II):147-161.

D'Altroy, Terence

2003 The Incas. Blackwell. Publishing.

D'Altroy, Terence; Ana Maria Lorandi; Veronica I. Williams; Milena Calderari; Christine Hastorf; Elizabeth DeMarrais; Melissa Hagstrum

2000 "Inka rule in the northern Calchaqui Valley, Argentina". Journal of Field Archaeology 27(No. 1):1 - 26.

D'Altroy, Terence; Christine A. Hastorf

1992 "The architecture and the contents of Inka State storehouses in the Xauxa Region of Peru". En Inka storage systems. T. LeVine, ed. Pp. 259 - 286. Norman and London: University of Oklahoma Press: Norman and London.

Dayton, Christopher

2008 Late prehistoric and modern irrigation agriculture in Torata, Peru. Doctoral Dissertation, Boston University.

Diez de San Miguel, Garci

1964 [1567] "Visita hecha a La provincia de Chucuito por Garci Diez de San Miguel". En Documentos regionales para la Etnonhistoria Andina, N. 1. Lima.

Flores, Capriles; Carlos Revilla Herrero

2006 "Ocupacion Inka en la region Kallawaya: oralidad, etnohistoria y arqueologia de Camata, Bolivia”. Chungara 38(No.2):223 - 238 .

Garcilaso de la Vega, Inca

1966 [1609] Royal commentaries of the Incas. Volume I and II. Austin \& London: University of Texas Press.

Goldstein, David; Lizette Muñoz Rojas

2007 Camata Tambo Project - Reporte Macrobotánico. Lima.

Güillaume - Gentil, Nicolas

1992 Camata Pueblo and Camata Tambo. Tesis de Maestria, Universite de Neuchatel. 
Helsley, Anne

1980 Excavations at Cerro Tambo Real Lambayeque, Peru. Bachelor of Arts., Princeton University.

Huaman, Lucho

2009 "Reporte preliminario de Palinología de muestras de sedimentos de los sitios arqueológicos Camata, Torata, Camata Tambo y Chuquibamba". En Laboratorio de Palinologia Eु Paleobotánica, LID, Facultad de Ciencias y Filosofía - Universidad Peruana Cayetano Heredaria. Lima.

Hyslop, John

1984 The Inka road system. New York: Institute of Andean Research.

Idrovo, Jaime

1998 "Tomebamba: primera fase de conquista incasica en los Andes Septentrionales. Los Cañaris y la conquista Incasica del austro ecuatoriano". En La Frontera del Estado Inca. T.D.y.P. Netherly, ed. Pp. 71 - 84. Quito: Fundacion Alexander Von Humbolt - ABYA-YALA.

INC

2004 Proyecto Qhapaq Nan. Informe de Campaña 2002 -2004. Lima: Instituto $\mathrm{Na}$ cional de Cultural del Perú.

Julien, Catherine

1991 Condesuyo: The political division of territory under Inca and Spanish rule. Boon: Bonner Amerikanistische Studien.

LeVine, Terry

1992 "Introduction. The study of storage systems". En Inka storage systems. T. LeVine, ed. Pp. 3 -28. London: University of Oklahoma Press: Norman and London.

\section{Llagostera, Agustin}

1976 "Hipótesis sobre la expansión incaica en la vertiente occidental de los Andes Meridionales". Anales de la Universidad del Norte 10, Antofagasta. (Homenaje al Dr Gustavo Le Paige, H. Niemeyer ed.):203 - 218 .
Mccormac, Gerry; Alan G. Hogg; Paul G. Blackwell; Caitlin E. Buck; Thomas F. G. Higham; Paula Reimer

2004 "SHCa104 Southern Hemisphere Calibration, 0-11.0 cal kyr BP”. Radiocarbon 46(3):1087-1092.

Montenegro y Ubaldi, Juan Antonio

1906 "Noticia de Moquegua". Revista Histórica 1(1):70 -109.

Morris, Craig

1986 "Storage, supply, and redistribution in the economy of the Inka state". En Anthropological History of Andean Polities. J. Murra, Nathan Watchel, and Jacques Revel, ed. Pp. 59-68. Paris: Cambridge University Press.

1992a "Foreword". In Inka storage systems. T. LeVine, ed. Pp. ix-xiii. Norman and London: University of Oklahoma Press.

1992b "Huanuco Pampa and Tunsukancha: major and minor nodes in the Inka storage network". En Inka storage systems. T. LeVine, ed. Pp. 151 - 175. Norman and London: University of Oklahoma Press: Norman and London.

1992c "The Technology of highland Inka food storage". En Inka storage systems. T. LeVine, ed. Pp. 237 - 258. Norman and London: University of Oklahoma Press.

Moseley, Michael

2001 Incas and their ancestors: the Archaeology of Peru. London, Eng; New York, N.Y.: Thames and Hudson.

Muñoz, Iván

1996 "Integracion y complementariedad en las sociedades prehispánicas en el extremo norte de Chile: hipótesis de trabajo”. En La Integración surandina cinco siglos después. M.I.A. Xavier Albo, Jorge Hidalgo, Lautraro Nunez, Agustin Llagostera, Maria Isabel Remy, Bruno Revesz, ed. Pp. 161-176. Cusco: Centro de Estudios Regionales Andinos "Bartolome de Las Casas".

1998 "La expansion Incaica y su vinculacion 
con las poblaciones de los valles occidentales del extremo Norte de Chile". En Tawantinsuyo. Pp. 127 - 137, Vol. 5.

Muñoz, Iván; Juan Chacama

2006 Complejidad social en las alturas de Arica: territorio, etnicidad y vinculacion con el Estado Inca. 250 vols: Universidad de Tarapaca, Arica - Chile.

Netherly, Patricia

1993 "The nature of the Andean State". En configurations of power. Holistic anthropology in theory and practice. J.a.P.N. Henderson, ed. Pp. 11-35. New York: Cornell University Press.

Pärssinen, Martti

1992 Tawantinsuyu. The Inca State in Its political organization. Helsinski: The Finnish Historical Society.

Pärssinen, Martti; Ari Siiriainen

1997 "Inka-Style ceramics and their chronological relationship to the Inka Expansion in the couthern Lake Titicaca Area (Bolivia)". Latin American Antiquity 8(3):255 - 271.

2003 Andes orientales y amazonia occidental. Ensayos entre la historia y la arqueologia de Bolivia, Brasil y Peru. La Paz: Producciones CIMA.

Reycraft, Richard Martin

1998 Terminal Chiribaya Project: The Archaeology of human response to natural disaster in South Coastal Peru. Disertación Doctoral, The University of New Mexico.

Rowe, John

1946 "Inca culture at the time of the Spanish conquest". En Handbook of South American Indians. J.H. Steward, ed. Pp. 183-330, Vol. 2. Washington, D.C.: Smithsonian Institution, Bureau of American Ethnology Bulletin 143.

Rowstorowski, Maria

1986 "La Region del Colesuyo". Chungara 16/17:127-135.
Sarmiento de Gamboa, Pedro

2007 [1572] The history of the Incas. Austin: University of Texas Press.

Sinopoli, Carla

2001 "Empires". En Archaeology at the Millennium. A Sourcebook. G.F.a.D. Price, ed. Pp. 439-495: Kluwer Acade$\mathrm{mic} /$ Plenum publishers.

Smyth, Michael

1991 "Modern Maya storage behavior. Ethnoarchaeological case examples from the Puuc Region of Yucatan". En University of Pittsburgh Memoirs in Latin American Archaeology. Pittsburgh.

Stanish, Charles

1989 "Household archaeology: testing models of zonal complementarity in the South Central Andes". American Anthropologist 91:7-24.

1991 "A late pre-hispanic ceramic chronology for the upper Moquegua Valley, Peru". Fieldiana 16:1-68.

1992 Ancient andean political economy. Austin: University of Texas Press.

1997 "Nonmarket imperialism in the prehispanic Americas: The Inka occupation of the Titicaca Basin". Latin American Antiquity 8(3):195-216.

1998 "Los periodos Estuquina e Inca en la prehistoria de Moquegua". En Moquegua, Los primeros doce mil años. K. Wise, ed. pp. 103-109. Moquegua: Museo Contisuyo.

Stehberg, Ruben

1991-1992 "El límite inferior cronológico de la expansión incaica a Chile". Xama 4-5:83-89.

Stein, Gil

2002a "Colonies without colonialism: A trade diaspora model of fourth Millennium B.C. Mesopotamian enclaves in Anatolia". En Archaeology and Colonialism. C.a.J.P. Lyons, ed. Pp. 27 - 64. Los Angeles, CA: The Getty Research Institute Publications Program. 
2002b "From passive periphery to active agents: emerging perspectives in the archaeology of interregional interaction". American Anthropologist 104(3):903-916.

Trelles Arestegui, Efrain

1991 Lucas Martinez Vegazo. Funcionamiento de una encomienda peruana inicial (segunda edicion corregida y aumentada). Lima: Pontificia Universidad Catolica del Peru. Fondo Editorial.

Tschauner, Hartmut

2001 Socioeconomic and political organization in the late Prehispanic Lambayeque Sphere, northern North Coast of Peru, Harvard University.

Uhle, Max

1969 Estudios sobre historia incaica. Lima: Universidad Nacional Mayor de San Marcos.

Van Buren, Mary

1996 "Rethinking the vertical Archipielago: ethnicity, exchange, and history in the South Central Andes". American Anthropologist 98(2):338-351.

Watchel, Nathan

1982 "The mitimas of the Cochabamba Valley: the colonization policy of Huayna
Capac". En The Inca and Aztec States 1400 - 1800. G. Collier, Renato Rosaldo, and John Wirth, ed. Pp. 199 - 235. New York: Academic Press, Inc.

Werge, Robert

1977 "Potato storage systems in the Mantaro Valley Region of Peru”. En Socioeconomic unit. Centro Internacional de la Papa Lima, Peru. Lima, Peru.

Wernke, Steve

2003 An archaeo-history of Andean community and landscape: the Late Prehispanic and Early Colonial Colca Valley, Peru. University of Wisconsin-Madison.

Williams, Patrick Ryan

1997 The role of disaster in the development of agriculture and the evolution of social complexity in the South-Central Andean Sierra. Disertación Doctoral, University of Florida.

2006 "Agricultural innovation, intensification, and sociopolitical development: the case of highland irrigation agriculture on the Pacific Andean watersheds". En Agricultural strategies. C.S.a.J. Marcus, ed. Los Angeles: Cotsen Institute of Archaeology. 